\title{
The Cysteine Protease Inhibitor, E64d, Reduces Brain Amyloid- $\beta$ and Improves Memory Deficits in Alzheimer's Disease Animal Models by Inhibiting Cathepsin B, but not BACE1, $\beta$-Secretase Activity
}

\author{
Gregory Hook $^{\mathrm{a}, *}$, Vivian Hook ${ }^{\mathrm{b}}$ and Mark Kindy $\mathrm{y}^{\mathrm{c}, \mathrm{d}, \mathrm{e}}$ \\ ${ }^{a}$ American Life Science Pharmaceuticals, San Diego, CA, USA \\ ${ }^{\mathrm{b}}$ Skaggs School of Pharmacy and Pharmaceutical Sciences, Departments of Neuroscience, Pharmacology, \\ and Medicine, School of Medicine, Univ. of Calif., San Diego, La Jolla, CA, USA \\ ${ }^{\mathrm{c}}$ Ralph H. Johnson VA Medical Center, Charleston, SC, USA \\ ${ }^{\mathrm{d}}$ Department of Neurosciences, Medical University of South Carolina, Charleston, SC, USA \\ e Applied Neurotechnology, Inc. Charleston, SC, USA
}

Handling Associate Editor: Ottavio Arancio

\begin{abstract}
The cysteine protease cathepsin B is a potential drug target for reducing brain amyloid- $\beta(A \beta)$ and improving memory in Alzheimer's disease (AD), as reduction of cathepsin $B$ in transgenic mice expressing human wild-type amyloid- $\beta$ protein precursor $(\mathrm{A} \beta \mathrm{PP})$ results in significantly decreased brain $\mathrm{A} \beta$. Cathepsin $\mathrm{B}$ cleaves the wild-type $\beta$-secretase site sequence in $\mathrm{A} \beta P P$ to produce $A \beta$, and cathepsin $B$ inhibitors administered to animal models expressing A $\beta P P$ containing the wild-type $\beta$ secretase site sequence reduce brain $A \beta$ in a manner consistent with $\beta$-secretase inhibition. But such inhibitors could act either by direct inhibition of cathepsin $B \beta$-secretase activity or by off-target inhibition of the other $\beta$-secretase, the aspartyl protease BACE1. To evaluate that issue, we orally administered a cysteine protease inhibitor, E64d, to normal guinea pigs or transgenic mice expressing human $A \beta P P$, both of which express the human wild-type $\beta$-secretase site sequence. In guinea pigs, oral E64d administration caused a dose-dependent reduction of up to $92 \%$ in brain, CSF, and plasma of $A \beta_{40}$ and $A \beta_{42}$, a reduction of up to $50 \%$ in the C-terminal $\beta$-secretase fragment (CTF $\beta$ ), and a $91 \%$ reduction in brain cathepsin B activity, but increased brain BACE1 activity by $20 \%$. In transgenic AD mice, oral E64d administration improved memory deficits and reduced brain $A \beta_{40}$ and $A \beta_{42}$, amyloid plaque, brain CTF $\beta$, and brain cathepsin $B$ activity, but increased brain BACE1 activity. We conclude that E64d likely reduces brain $A \beta$ by inhibiting cathepsin B and not BACE1 $\beta$-secretase activity and that E64d therefore may have potential for treating $\mathrm{AD}$ patients.
\end{abstract}

Keywords: Alzheimer disease, amyloid- $\beta$, BACE1, cathepsin B, guinea pig, memory deficits, oral E64d, transgenic mice

\footnotetext{
${ }^{*}$ Correspondence to: Gregory Hook, Ph.D., American Life Science Pharmaceuticals, 3030 Bunker Hill Street, Suite 104, San Diego, CA 92109. Tel.: 858273 3900; E-mail: ghook@ alspinc.com.
}

\section{INTRODUCTION}

Alzheimer's disease (AD) results in the progressive loss of cognitive function and the accumulation of neurotoxic amyloid- $\beta$ peptides $(A \beta)$ in the brain 
[1-3]. The abnormal accumulation of $\mathrm{A} \beta$ has been demonstrated as a major disease factor based largely on studies in transgenic mouse models in which the overproduction of brain $A \beta$ results in memory deficits and brain amyloid plaque, which mimics that seen in $\mathrm{AD}$ patients [4-6]. Compounds which reduce brain $\mathrm{A} \beta$ are thought to be potentially disease-modifying therapeutics because they would reduce the abnormal accumulation of the $\mathrm{A} \beta$ peptides and thereby diminish the likely cause of the disease.

Brain $\mathrm{A} \beta$ production and its neurotoxicity, as well potential methods of pharmaceutical intervention to reduce that production and toxicity, have been the subject of many reviews [7-12]. Briefly, $A \beta$ peptides are cleaved out of the amyloid- $\beta$ protein precursor (A $\beta P P$ ) by proteases, functionally called $\beta$ - and $\gamma$-secretase, which cleave $\mathrm{A} \beta \mathrm{PP}$ at the $\mathrm{N}$ - and $\mathrm{C}$-termini of the $A \beta$ peptides, respectively. $\beta$-secretase first cleaves $\mathrm{A} \beta \mathrm{PP}$ to produce the $\mathrm{C}$-terminal $\beta$-secretase fragment (CTF $\beta$ ) from which the $\gamma$-secretase produces $A \beta$ of varying lengths, the most common of which contain 40 $\left(A \beta_{40}\right.$ or $\left.A \beta_{1-40}\right)$ or $42\left(A \beta_{42}\right.$ or $\left.A \beta_{1-42}\right)$ amino acids. Soluble $A \beta$ monomers form into soluble oligomers, which can then form fibrils and eventually into insoluble brain amyloid plaque, but soluble $A \beta$ oligomers appear to correlate with the cognitive decline seen in $\mathrm{AD}$ [13]. Another protease, which is functionally called the $\alpha$-secretase, competes with the $\beta$-secretase for $\mathrm{A} \beta \mathrm{PP}$ cleavage and produces soluble $\mathrm{A} \beta \mathrm{PP}$ alpha $(\mathrm{sA} \beta \mathrm{PP} \alpha)$, which is neuroprotective $[10,14,15]$. A $\beta$-secretase inhibitor is a particularly attractive means of reducing brain $A \beta$ because it would reduce both forms of neurotoxic $A \beta$ and increase neuroprotective sA $\beta P P \alpha$.

The vast majority of $\mathrm{AD}$ patients develops sporadic $\mathrm{AD}$ and produce $\mathrm{A} \beta$ by $\beta$-secretase cleavage of the normal wild-type (wt) $\beta$-secretase cleavage site sequence in $A \beta P P[8,16]$. Thus, a $\beta$-secretase inhibitor must be able to inhibit wt $\beta$-secretase site cleavage if it is to be effective in treating most AD patients. A good model for evaluating the effects of $\beta$-secretase inhibitors on natural human wt $\beta$-secretase production of $A \beta$ is the normal guinea pig, which expresses $\mathrm{A} \beta \mathrm{PP}$ containing the human wt $\beta$-secretase site sequence [17-19]. But guinea pigs do not develop brain plaque or memory deficits and thus cannot be used to evaluate the pathology or behavior of AD. Transgenic mice expressing human $\mathrm{A} \beta \mathrm{PP}$, having mutations that cause overexpression of brain $A \beta$, develop brain plaque and memory deficits, but none of these models perfectly reflects $\mathrm{AD}$ and they may represent asymptomatic $\mathrm{AD}[20]$. $\mathrm{A} \beta P P$ having mutations at the $\beta$-secretase cleavage site sequence, called the Swedish mutation (Swe), is widely used in transgenic mouse models [21]. Only one family expresses A $\beta$ PPSwe and those individuals develop familial $\mathrm{AD}$, which is characterized by more brain $\mathrm{A} \beta$ accumulation and a much earlier onset of the disease than in sporadic $\mathrm{AD}[22]$. But $\beta$-secretase cleavage of the wt and Swe $\beta$-secretase sites may differ and thus inhibitors of the Swe $\beta$-secretase site cleavage may or may not be effective for treating most $\mathrm{AD}$ patients [23]. The effects of $\beta$-secretase inhibitors on wt $\beta$-secretase activity, brain plaque and memory deficits can be studied in transgenic mice expressing A $\beta P P$ containing a mutation near the $\gamma$-secretase site sequence but which has the wt $\beta$-secretase site sequence. One such mutant $\mathrm{A} \beta \mathrm{PP}$ is known as the London mutant (AßPPLon) and is found in 30 families, which develop familial AD [24-26] (AD\&FTD Mutation Database http://www.molgen.ua.ac.be/ADMutations).

Two proteases identified as $\beta$-secretases exhibit very different cleavage efficiencies for the Swe mutant versus wt $\beta$-secretase site sequences [23]. The aspartyl protease, BACE1, is the most well known $\beta$-secretase and was originally identified as such in transfected cells and in transgenic animal models containing Swe $\beta$ secretase site sequence [27-31]. BACE1 cleaves the Swe $\beta$-secretase site sequence but barely cleaves the wt $\beta$-secretase site sequence [32-34]. The cysteine protease cathepsin B has also been identified as a $\beta$ secretase in models expressing the wt $\beta$-secretase site sequence, but in contrast to BACE1, cathepsin B readily cleaves the wt $\beta$-secretase site but does not cut the Swe mutant $\beta$-secretase site [35-37].

Although gene knockout and siRNA studies have clearly shown that cathepsin $\mathrm{B}$ is a valid target for reducing $A \beta$ in models expressing the wt $\beta$-secretase site sequence $[36,38]$, cathepsin $B$ 's role as a $\beta$ secretase is controversial in large part because the relationship between cathepsin B and BACE1 $\beta$ secretase activity is unclear. For example, it is possible that the reduction in $A \beta$, which results from deleting or suppressing the cathepsin B gene, may be due to an indirect inhibition of BACE1 $\beta$-secretase activity and cathepsin $B \beta$-secretase inhibition may be of only minor importance.

Previously, we showed that cathepsin B inhibitors reduce brain $A \beta$ in the guinea pig and transgenic A $\beta$ PPLon mouse models [39-41] and improve memory deficits and reduce brain amyloid plaque in the transgenic A $\beta$ PPLon mouse model [41]. But in those studies, cathepsin B inhibitors were delivered directly to the brain by intracerebroventricular (icv) administration and no evaluation of brain BACE1 and cathepsin 
$\mathrm{B}$ activities were made. Thus, those studies established the proof-of-principle that cathepsin B inhibitors can reduce brain $A \beta$, plaques, and memory deficits. The studies did not show that cathepsin B inhibitors could be therapeutically developed because icv administration is not an acceptable means of treating $\mathrm{AD}$ patients. Moreover, they did not determine the relative importance in vivo of brain BACE1 and cathepsin $B \beta$-secretase inhibition in reducing brain $A \beta$ by a cathepsin $\mathrm{B}$ inhibitor.

To evaluate these issues, we studied the effects of oral administration of a small molecule, cysteine protease inhibitor E64d ((2 S,3 S)-trans-epoxysuccinyl-Lleucylamido-3-methylbutane ethyl ester, also known as EST and loxistatin, $342.2 \mathrm{~mol} \mathrm{wt}$ ) in either the guinea pig or transgenic A $\beta P P L o n$ mouse model. Oral E64d administration to either model caused a large dosedependent reduction in brain $\mathrm{A} \beta, \mathrm{CTF} \beta$, and cathepsin $\mathrm{B}$ activity, but increased $\mathrm{sA} \beta \mathrm{PP} \alpha$ and BACE1 activity relative to controls. Importantly, feeding E64d chow to transgenic A $\beta P P L o n$ mice also improved spatial memory deficits, and reduced brain $A \beta$ and amyloid plaque relative to controls. These data are consistent with E64d inhibiting $\beta$-secretase activity and show that the compound does not act by inhibiting BACE1 $\beta$-secretase activity, but most likely acts by inhibiting cathepsin B $\beta$-secretase activity. These data show also that oral E64d administration is efficacious in AD animal models expressing the A $\beta P P$ containing the human wt $\beta$-secretase site sequence found in most $\mathrm{AD}$ patients and, thus, it may have potential as an oral $\mathrm{AD}$ therapeutic agent.

\section{MATERIALS AND METHODS}

\section{E64d}

E64d is a prodrug ethyl ester of its biologically active acid form, E64 c, and is rapidly hydrolyzed in the gut to E64 c when it is orally administered. E64 c then circulates systemically [42]. E64 c permanently inhibits cysteine proteases by covalently binding to the sulfhydryl groups in the active site of the protease [42]. Thus, E64 c irreversibly binds to the active site of human papain-like cysteine proteases, B, C, F, H, K, L, O, S, W, V, and Z [43, 44], and calcium ion-dependent papain-like cysteine proteases (calpain) [45]. E64 c does not inhibit BACE1 activity [23].

E64d was synthesized by American Life Science Pharmaceuticals (San Diego, CA) using methods developed and modified from those previously described [46]. Purity was determined to be $99 \%$ by reverse-phase high-pressure liquid chromatograph (RP-HPLC) assay, which was confirmed against a qualified reference standard. The identity of the compound was confirmed by ${ }^{1} \mathrm{H}$ nuclear magnetic resonance (NMR), melting point, elemental analysis and liquid chromatography mass spectroscopy (LCMS) (data not shown). E64d exhibited excellent stability with 99\% of the compound remaining after a 5-week stability test at $60^{\circ} \mathrm{C}$ (data not shown). However, E64d is also commercially available from various suppliers (e.g., Calbiochem, San Diego).

\section{Animal models}

\section{Guinea pigs}

Guinea Pigs (male, Hartley strain, average weight $400 \mathrm{~g}$ corresponding to animals about 6 weeks old) were obtained from Charles River (Wilmington, MA). The animals were given free access to standard chow and water before and during the experiment.

\section{Transgenic AD mice}

Male transgenic mice expressing human A $\beta P P$ containing the wt $\beta$-secretase site and the London mutant $\beta$-secretase site sequences were generated by Applied Neurotechnology, Inc. (Charleston, SC) by methods previously described [41]. Briefly, A $\beta P P L o n$ was generated using site-directed mutagenesis to insert the V717I London mutation into human A $\beta P P$ cDNA. The mouse strain was created in a $\mathrm{C} 57 \mathrm{Bl} / 6$ mouse background using the Thy-1.2 expression cassette driven by the Thy-1 promoter containing an SV40 polyadenylation site [47]. Mice were given free access to food and water before and during the experiment.

From about 3 months of age onwards, AßPPLon mice express soluble $A \beta$ aggregates and develop cognitive impairment but they do not appreciably develop brain plaque until at least about 12 months of age and thus their cognitive impairment is dissociated from plaque formation $[25,26]$. In order to evaluate the effects of E64d before and after brain plaque formation occurs, two age groups of transgenic A $\beta$ PPLon mice were studied, young ( 6 to 9 months of age) and old (12 to 15 months of age).

\section{Oral formulations}

\section{Gavage formulation}

Delivering a drug by gavage offers the advantage of accurate dosing but is traumatic and thus only suitable for relatively short dosing periods (up to about a week). Delivery by gavage was used for the guinea pig stud- 
ies. E64d was suspended in $\mathrm{Me}_{2} \mathrm{SO}$ at the indicated concentrations $(0.1,1.0,5$, and $10 \mathrm{mg} / \mathrm{kg})$ and administered by gavage daily using a feeding tube. Vehicle control animals were treated by gavage of $\mathrm{Me}_{2} \mathrm{SO}$ alone.

\section{Mouse chow formulation}

Delivering a drug by doped chow feeding allows for extended dosing periods without trauma but results in less accurate dosing because individual animals consume variable amounts of chow. Doped chow feeding was used for the transgenic AD mice experiments. A $10 \mathrm{mg} / \mathrm{kg} /$ day E64d oral dose was maximally effective at lowering brain $A \beta$ and cathepsin $B$ activity in guinea pigs and thus a calculated dose of that amount was administered to the transgenic mice in doped chow. E64d doped mouse chow was prepared in the mouse chow routinely used to feed the transgenic AD mice (2018, Teklad Global 18\% Protein Rodent Diet, Harlan Laboratories, Inc. of Madison, WI). Briefly, 40 milligrams $(\mathrm{mg})$ of E64d per kilogram $(\mathrm{kg})$ of chow was processed into standard 12.7 millimeter pellets according to the manufacturer's procedure. The resulting doped chow was analyzed by RP-HPLC and found to contain $20 \mathrm{mg}$ of E64d per $\mathrm{kg}$ of chow. RP-HPLC studies showed that only $50 \%$ of the E64d extracted from spiked chow is detected (data not shown). Thus the doped chow actually contained about $40 \mathrm{mg}$ E64d per kg of chow. The mice consume on average about 5 grams (gm) of chow per day and had an average body weight of about $20 \mathrm{gm}$. Thus, on average, mice ate a daily E64d dose of $10 \mathrm{mg} / \mathrm{kg}$.

\section{Oral dosing}

\section{Guinea pig gavage dosing}

Guinea pigs were treated by gavage daily for one week. Guinea pigs were lightly anesthetized with isoflurane prior to treatment. $250 \mu \mathrm{l}$ of compound solution per animal per day was administered and the animals were sacrificed $4 \mathrm{~h}$ after the last dosing.

\section{Mouse chow dosing}

Two dose regimes, 1 month and 3 months, were used for both young (6 months old) and old (12 months old) transgenic mice. All animals were fed normal chow up to the appropriate age ( 6 or 12 months) at which age the experimental animals were switched to feeding on E64d doped chow for 1 or 3 months. Thus, the experimental young mice were fed doped chow beginning at 6 months of age and continued with that fed until they were either 7 or 9 months old. Similarly, old mice were fed doped chow beginning at 12 months of age and continued until they were 13 or 15 months old. The experimental mice were fed doped chow while training for and being tested in the Morris water maze test. Control mice received normal chow throughout their life. All animals were fed ad libitum. No difference was observed in the amount of E64d doped and normal chow consumed by the different groups (data not shown).

\section{Analyses}

\section{Spatial memory deficits and memory retention}

The memory deficits in transgenic A $\beta$ PPLon mice was measured using the Morris water maze test [48, 49]. Briefly, the spatial memory capability of each animal was assessed by the Morris water maze swimming test (700-0718-4 W SD Instruments)[41]. Mice were individually trained in a 1.2-m open field water maze in a pool filled with water to a depth of $30 \mathrm{~cm}$ and maintained at $25^{\circ} \mathrm{C}$ and rendered opaque by the addition of a small amount of nontoxic white powder. Four positions around the edge of the tank were arbitrarily designated north $(\mathrm{N})$, south $(\mathrm{S})$, east $(\mathrm{E})$, and west $(\mathrm{W})$; to provide four alternative start positions and define the division of tank into four quadrants: NE, SE, SW, and NW. An escape platform $(10 \mathrm{~cm}$ square and white) was placed $1 \mathrm{~cm}$ below the surface of the water and invisible to the mice. All animals underwent nonspatial pretraining for 3 consecutive days, which prepared the animals for the final behavioral test to determine the retention of memory to find the platform. The day following the nonspatial pretraining, the hidden platform was placed in the center of one quadrant of the pool. The animal was released into the pool facing the pool wall in a random fashion and the time (latency period) and the distance traveled from the release to the animal standing on the platform was measured using video recording (Smart Video Tracking System; SD Instruments). On the day after the last training session, the platform was removed and a spatial probe test conducted in which each mouse was allowed to search for the platform for 60 seconds (memory retention) and the percent time spent in the NE target quadrant where the platform had been was determined.

\section{Brain amyloid plaque}

Amyloid load was assessed in brain sections from mice by methods previously used [41]. Amyloid plaques were located by immunostaining for $A \beta$ (A $\beta$ antibody 10D5, Elan Pharmaceuticals). Brain tissues were fixed in $4 \%$ paraformaldehyde and then in $4 \%$ par- 
formaldehyde and $30 \%$ sucrose for $24 \mathrm{~h}$ each at $4{ }^{\circ} \mathrm{C}$. Tissues were washed in buffered saline and transferred to an optimum cutting temperature (O.C.T.) medium. Cryosections were cut and blocked with normal serum, incubated with anti-A $\beta$ and stained with diaminobenzoic acid (Vector ABC Elite kit, Vector Laboratories). Bright field light microscopy imaged brain areas from which stained amyloid areas were quantitated using image analysis (NIH Image software).

\section{Brain $A \beta$ analysis}

The brain $A \beta$ analysis method was that previously described for guinea pigs and transgenic AD mice [39-41]. Animals were sacrificed and brain extracts were prepared as previously described. Briefly, brain extracts were homogenized $(1: 3$ weight/volume of buffer) in buffer of $5 \mathrm{M}$ guanidine $\mathrm{HCl}$ in $50 \mathrm{mM}$ Tris- $\mathrm{HCl}, \mathrm{pH} 7.6,150 \mathrm{mM} \mathrm{NaCl}$, plus protease inhibitors (Sigma). Homogenates were diluted to $0.5 \mathrm{M}$ guanidine and centrifuged (200,000 $\mathrm{g}$ for $20 \mathrm{~min})$, and supernatant and pellet fractions were collected. Protein content was determined by the Bradford method [50]. Enzyme-linked immunosorbent assays (ELISAs) measured $A \beta$ peptides by methods previously described $[51,52]$. The pellet from the brain extract procedure was sonicated in $6 \mathrm{M}$ guanidine and centrifuged at $200,000 \mathrm{~g}$ for $20 \mathrm{~min}$ at $4^{\circ} \mathrm{C}$, and the supernatant was diluted to $0.5 \mathrm{M}$ guanidine. The two supernatants were combined, and $A \beta_{40}$ and $A \beta_{42}$ were determined using ELISA kits specific for each peptide (IBL, JP27718 and JP27711).

\section{$C S F A \beta$}

CSF was collected from the guinea pig brains and protease inhibitors were added and $A \beta_{40}$ and $A \beta_{42}$ were determined using ELISA kits specific for each peptide (IBL, JP27718, and JP27711).

\section{Plasma A $\beta$}

Plasma samples were collected from the guinea pigs following sacrifice, protease inhibitors were added and $A \beta_{40}$ and $A \beta_{42}$ were determined using ELISA kits specific for each peptide (IBL, JP27718 and JP27711).

\section{Brain CTF $\beta$ and $s A \&$ beta $; P P \alpha$}

$\mathrm{CTF} \beta$ and $\mathrm{sA} \beta \mathrm{PP} \alpha$ were determined by methods previously described [39-41]. Briefly, CTF $\beta$ and $\mathrm{sA} \beta \mathrm{PP} \alpha$ were determined in the pellet and supernatant fractions, respectively, from the brain extract by Western blot (antibody A8717 and antibody 6E10, respectively, Sigma). Relative amounts of CTF $\beta$ and
sA $\beta P P \alpha$ were assessed by densitometry of the Western blots.

\section{Brain cathepsin B activity analysis}

Cathepsin B activity was determined using a fluorometric assay kit from Abcam (ab65300) as described by the manufacturer.

\section{Brain BACE1 activity analysis}

The brain BACE1 activity was determined using a fluorometric assay kit from Abcam (ab65357) as described by the manufacturer.

\section{Animal treatment}

\section{Humane animal use}

Animal studies were conducted according to regulations by the NIH and as approved by the IACUC at the Medical University of South Carolina and Ralph H. Johnson VA Medical Center.

\section{Statistics}

10 guinea pigs and transgenic $\mathrm{A} \beta \mathrm{PP}$ mice were studied per group. Numerical data were collected and entered into GraphPad Prizm 5 software, which was used to graphically display and analyze the results.

The means of the guinea pig data were compared using ANOVA and Dunnett's multiple comparison tests, which compared the control group with the E64d treated groups. The means of the transgenic A $\beta$ PPLon mouse data were compared using unpaired t-test comparisons of age-matched animals receiving normal or E64d doped chow.

The guinea pig dose-response reduction curves were determined using linear regression two-phase exponential decay, one fast and on slow, least squares fit. The paired guinea pig and transgenic $\mathrm{A} \beta \mathrm{PP}$ mouse data were analyzed using linear regression analysis.

\section{RESULTS}

\section{Guinea pig data}

\section{Guinea pig $A \beta$}

Oral administration of E64d to guinea pigs resulted in a dose- dependent reduction in brain, CSF and plasma $A \beta_{40}$ and $A \beta_{42}$ (Fig. 1 A-F). All three compartments and both $A \beta$ forms had similar biphasic dose responses with a sharp reduction in $A \beta$ occurring between 0.0 to $1 \mathrm{mg} / \mathrm{kg} / \mathrm{day}$ dose with a more gradual 

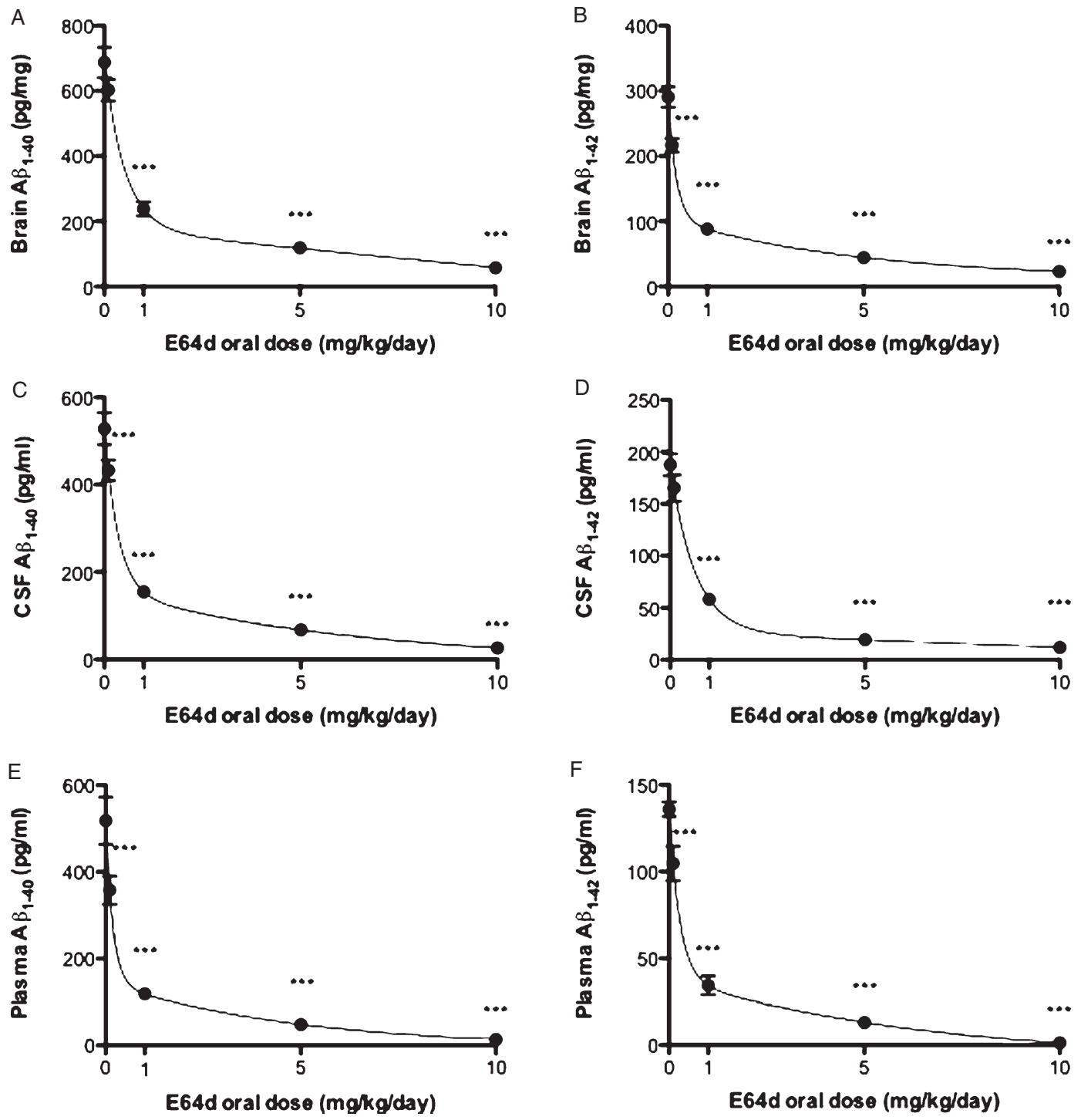

Fig. 1. E64d reduces brain, CSF, and plasma $A \beta_{40}$ and $A \beta_{42}$ in guinea pigs. Once-a-day oral administration of E64d for one week to guinea pigs results in similar biphasic dose-dependent reductions in (A) brain $A \beta_{40}$, (B) brain $A \beta_{42},(C) C S F A \beta_{40}$, (D) $C S F A \beta_{42}$, (E) plasma $A \beta_{40}$, and (F) plasma $A \beta_{42}$. The minimum effective dose was about $1 \mathrm{mg} / \mathrm{kg} /$ day. The maximum dose $(10 \mathrm{mg} / \mathrm{kg} / \mathrm{day}) \mathrm{caused}$ a $90 \%$ reduction or more in both $A \beta_{40}$ and $A \beta_{42}$ in all compartments. The guinea pig is a natural model of human wild-type $A \beta P P$ processing and, thus, the major reduction in $A \beta$ caused by oral E64d administration in that model suggests that the compound may have similar effects in humans. The fact that both $A \beta_{40}$ and $A \beta_{42}$ were similarly affected in all compartments is consistent with the compound inhibiting $\beta$-secretase production of $A \beta$. The mean and standard error of the mean (SEM) are displayed at each data point. For some data points, the error bars are smaller than the symbol representing the mean and, therefore, the error bars are not visible. Stars represent those E64d dose groups, which are statistically different from the control group (no E64d) (Dunnett's multiple comparison t-test $* * * p<0.05, n=10$ animals/group).

reduction between 1 and $10 \mathrm{mg} / \mathrm{kg} /$ day. The minimum effective dose in the guinea pig was about $1 \mathrm{mg} / \mathrm{kg} / \mathrm{day}$. The mean $A \beta_{40}$ and $A \beta_{42}$ in all compartments and was significantly less than the control group (no E64d) for all E64d doses equal or greater than $1 \mathrm{mg} / \mathrm{kg} /$ day. The highest dose, $10 \mathrm{mg} / \mathrm{kg} /$ day, achieved the maxi- mum reduction of about $92 \%$ lower than the control group (no E64d) in $A \beta_{40}$ and $A \beta_{42}$ in all compartments (brain, CSF, and plasma). These data are consistent with the inhibitor reducing $\beta$-secretase activity because $\beta$-secretase produces both $A \beta_{40}$ and $A \beta_{42}$ and both forms were similarly reduced. 


\section{Guinea pig brain $C T F \beta$}

E64d also caused a biphasic dose-dependent reduction in brain CTF $\beta$ (Fig. 2A, B). The mean CTF $\beta$ levels were significantly lower than the control group (no E64d) for E64d doses of $1 \mathrm{mg} / \mathrm{kg} /$ day or greater with the highest E64d dose resulting in the maximal reduction in CTF $\beta$ of about $50 \%$ lower than that of the control group. These data are also consistent with E64d reducing $\beta$-secretase activity because CTF $\beta$ is the cleavage product of $\beta$-secreatase.

\section{Guinea pig brain $s A \beta P P \alpha$}

E64d caused a dose-dependent increase in brain sA $\beta P P \alpha$ (Fig. 2 C, D). The mean sA $\beta P P \alpha$ levels were significantly higher than the no dose group for E64d doses of $5 \mathrm{mg} / \mathrm{kg} /$ day or greater with the highest E64d dose resulting in the maximum increase in $\mathrm{SA} \beta \mathrm{PP} \alpha$ of about $54 \%$ more than the control group. These data also support the hypothesis that E64d is reducing $\beta$ secretase activity because $\operatorname{sA} \beta P P \alpha$ is derived from $\mathrm{A} \beta \mathrm{PP} \alpha$-secretase cleavage, which competes with $\beta$ secretase cleavage of $\mathrm{A} \beta \mathrm{PP}$, and thus the inhibition of $\beta$-secretase activity provides more A $\beta P P$ for $\alpha$ secretase to produce more $\operatorname{sA} \beta P P \alpha$.

\section{Guinea pig brain cathepsin B activity data}

Similar to the $A \beta$ effect, oral E64d administration produced a biphasic dose-dependent reduction in brain cathepsin B activity (Fig. 3A). Again, there was a steep decline in brain cathepsin B activity between 0 to $1.0 \mathrm{mg} / \mathrm{kg} /$ day and a gradual decline between 1.0 to $10.0 \mathrm{mg} / \mathrm{kg} /$ day. The minimum effective dose was about $1 \mathrm{mg} / \mathrm{kg} /$ day with the highest E64d dose causing the maximum reduction in brain cathepsin B activity of about $91 \%$ lower than that of the control group. Thus, E64d reduces guinea pig brain cathepsin B activity in a manner which is consistent with the compound inhibiting cathepsin B $\beta$-secretase activity.

\section{Guinea pig brain BACE1 activity data}

In contrast, oral E64d administration produced a slight dose-dependent increase in brain BACE1 activity (Fig. 3B). The increase in BACE1 activity rises as the dose increases to $5.0 \mathrm{mg} / \mathrm{kg} / \mathrm{day}$ and levels off. The
A

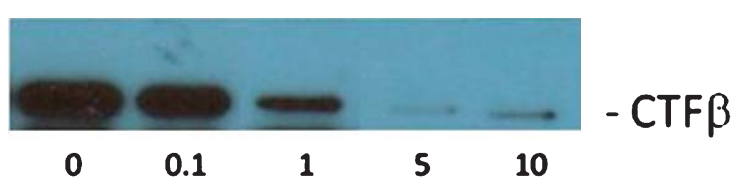

B
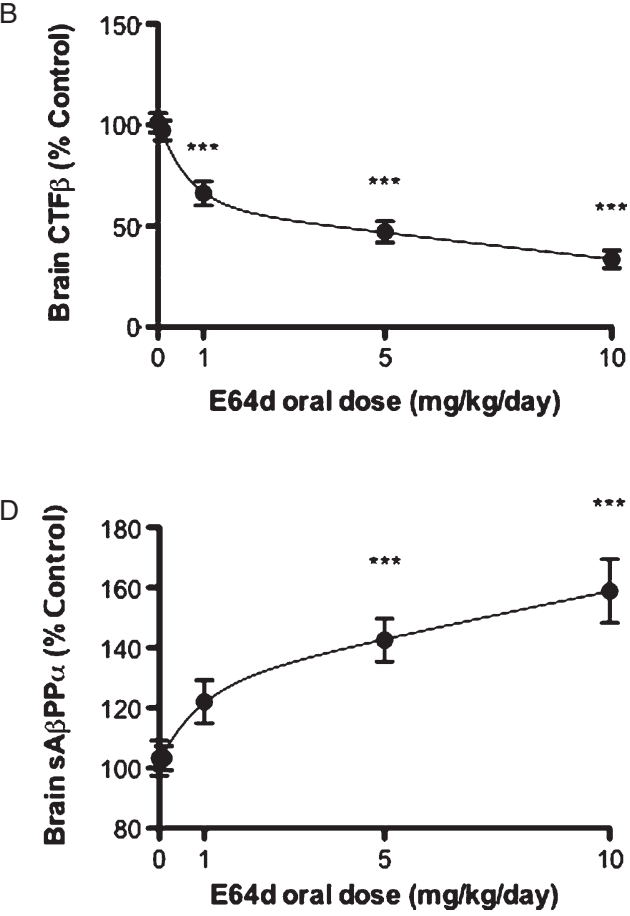

Fig. 2. E64d lowers and increases brain $\mathrm{CTF} \beta$ and $\mathrm{sA} \beta \mathrm{PP} \alpha$, respectively, in guinea pigs. Oral administration of E64d to guinea pigs caused a dose-dependent reduction in brain CTF $\beta$ with the maximum dose reducing CTF $\beta$ by more than $50 \%$ (Fig. $2 \mathrm{~A}, \mathrm{~B}$ ). CTF $\beta$ is a proteolytic product of $\beta$-secretase cleavage of $\mathrm{A} \beta \mathrm{PP}$ and thus these data are also consistent with the compound acting by inhibiting $\beta$-secretase activity. In contrast, the oral E64d treatment caused a dose-dependent increase in brain sA $\beta P P \alpha$ with the maximum dose increasing sA $\beta P P \alpha$ by about $54 \%$ (Fig. $2 \mathrm{C}, \mathrm{D})$. These data are consistent with E64d inhibiting $\beta$-secretase activity because sA $\beta P P \alpha$ is derived from A $\beta P P \alpha$-secretase cleavage, which competes with $\beta$-secretase cleavage of $A \beta P P$, and thus the inhibition of $\beta$-secretase activity provides more $A \beta P P$ for $\beta$-secretase to produce more sA $\beta P P \alpha$. The mean and SEM are displayed at each data point (Dunnett's multiple comparison test $* * * p<0.05, n=10$ animals/group). 

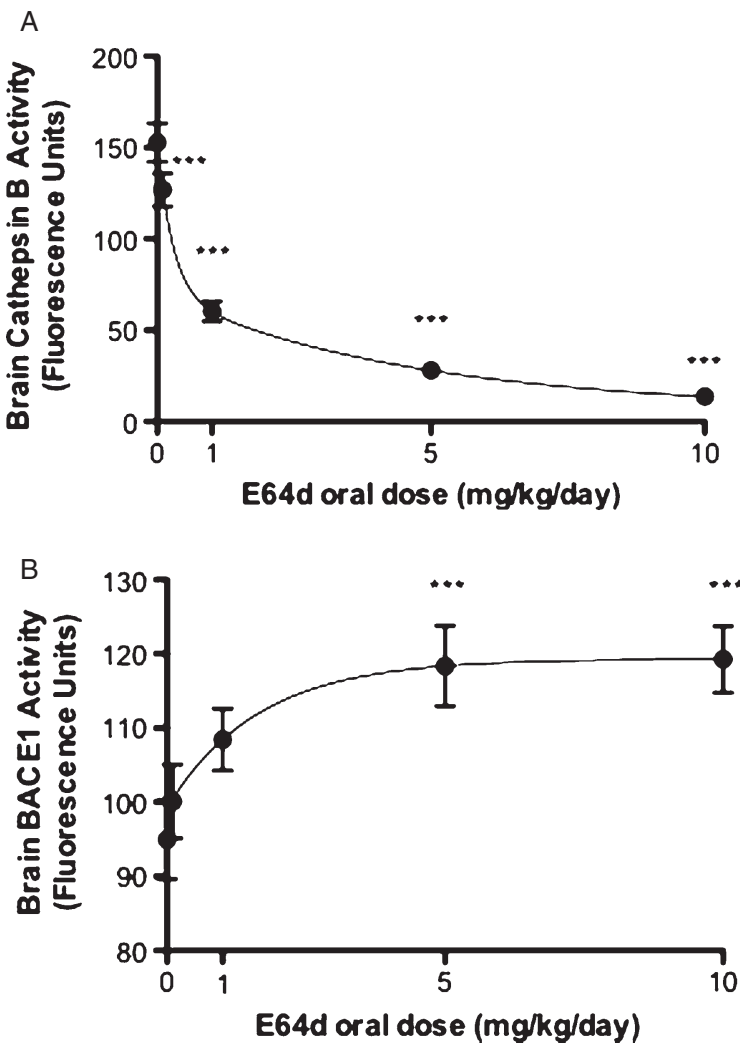

Fig. 3. E64d reduces and increases brain cathepsin B and BACE1 activities, respectively, in guinea pigs. Oral E64d administration to guinea pigs caused a biphasic dose-dependent reduction in brain cathepsin B activity with a minimum effective dose of about $1 \mathrm{mg} / \mathrm{kg} /$ day and the maximum dose lowering cathepsin B activity by $90 \%$ (Fig. 3A). As such, the brain cathepsin B effect is very similar to reduction in $A \beta$ caused by E64d. Cathepsin B inhibition by E64d is required if the compound acts by inhibiting cathepsin $B \beta$-secretase activity and thus these data support that mechanism of action. In contrast, that treatment caused an increase in brain BACE1 activity with the maximum dose increasing BACE1 activity by almost $20 \%$ (Fig. 3B). The increase in BACE1 activity rules out the hypothesis that E64d reduces brain $A \beta$ by inhibiting BACE1 $\beta$-secretase activity because BACE1 activity was increased. The mean and SEM are displayed at each data point (Dunnett's multiple comparison test $* * * p<0.05, n=10$ animals/group).

5.0 and $10.0 \mathrm{mg} / \mathrm{kg} /$ day doses resulted in the maximum increase in brain BACE1 activity of about $20 \%$ more than the control group. Thus, E64d increases guinea pig brain BACE1 activity, which rules out E64d acting by inhibiting BACE1 $\beta$-secretase activity in this model.

\section{Guinea pig brain $A \beta_{40}$ or $A \beta_{42}$ positively} correlated with brain cathepsin $B$ activity

Paired analysis of brain $A \beta_{40}$ or $A \beta_{42}$ and brain cathepsin $B$ activity from individual guinea pigs showed a very strong positive correlation for $A \beta_{40}$ or $\mathrm{A} \beta_{42}$, respectively (Fig. 4A, B). Thus, brain cathep$\sin B$ activity is strongly predictive of brain $A \beta_{40}$ and $A \beta_{42}$ levels, which is consistent with E64d reducing $\mathrm{A} \beta$ by inhibiting cathepsin $\mathrm{B} \beta$-secretase activity.

Guinea pig brain $A \beta_{40}$ or $A \beta_{42}$ negatively correlated with brain BACE1 activity

Paired analysis of brain $A \beta_{40}$ or $A \beta_{42}$ and brain BACE1 activity from individual guinea pigs showed a slight negative correlation for $A \beta_{40}$ or $A \beta_{42}$, respectively (Fig. 4C, D). Thus, brain BACE1 activity is not correlated with brain $A \beta$, which is inconsistent with E64d reducing brain $A \beta$ by inhibiting BACE1 $\beta$-secretase activity.

\section{Transgenic A $\beta P P L o n$ mice data}

\section{Mouse brain $A \beta$ data}

Young (6-9 months of age) and old (12 - 15 months of age) transgenic mice fed E64d doped chow for 1 or 3 months had significantly lower brain levels of $A \beta_{40}$ or $A \beta_{42}$ (Fig. $5 A, B$ ). The brain $A \beta_{40}$ or $A \beta_{42}$ reductions as a percentage of control for each age group and feeding schedule are summarized in Tables 1 and 2. The average brain $A \beta_{40}$ and $A \beta_{42}$ reduction for both treatments in both age groups was $62 \%$ and $58 \%$, respectively. Again, this data are consistent with the inhibitor reducing $\beta$-secretase activity because both $A \beta_{40}$ and $A \beta_{42}$ were similarly reduced.

\section{Mouse brain CTF\&beta;}

E64d feeding caused a significant $50 \%$ reduction in brain $\mathrm{CTF} \beta$ for both feeding schedules in both age groups relative to controls (Fig. 6A, B, C). These data are also consistent with E64d reducing $\beta$-secretase activity because CTF $\beta$ is the cleavage product of $\beta$ secretase and it is reduced with treatment.

\section{Mouse brain $s A \beta P P \alpha$}

E64d feeding caused a significant increase in brain $\mathrm{sA} \beta \mathrm{PP} \alpha$ for both feedings and in both age groups (Fig. 6D, E, F). Treatment for one or 3 months in the young or old animals resulted in a $21 \%$ or $34 \%$ increase, respectfully, in brain $\mathrm{sA} \beta \mathrm{PP} \alpha$ relative to controls. As discussed above, these data also support the hypothesis that E64d is reducing $\beta$-secretase activity because $\beta$-secretase activity inhibition increases $\mathrm{sA} \beta \mathrm{PP} \alpha$.

\section{Mouse brain cathepsin B activity}

The E64d treatment for one or 3 months in the young and old mice caused on average a $77 \%$ reduction in 

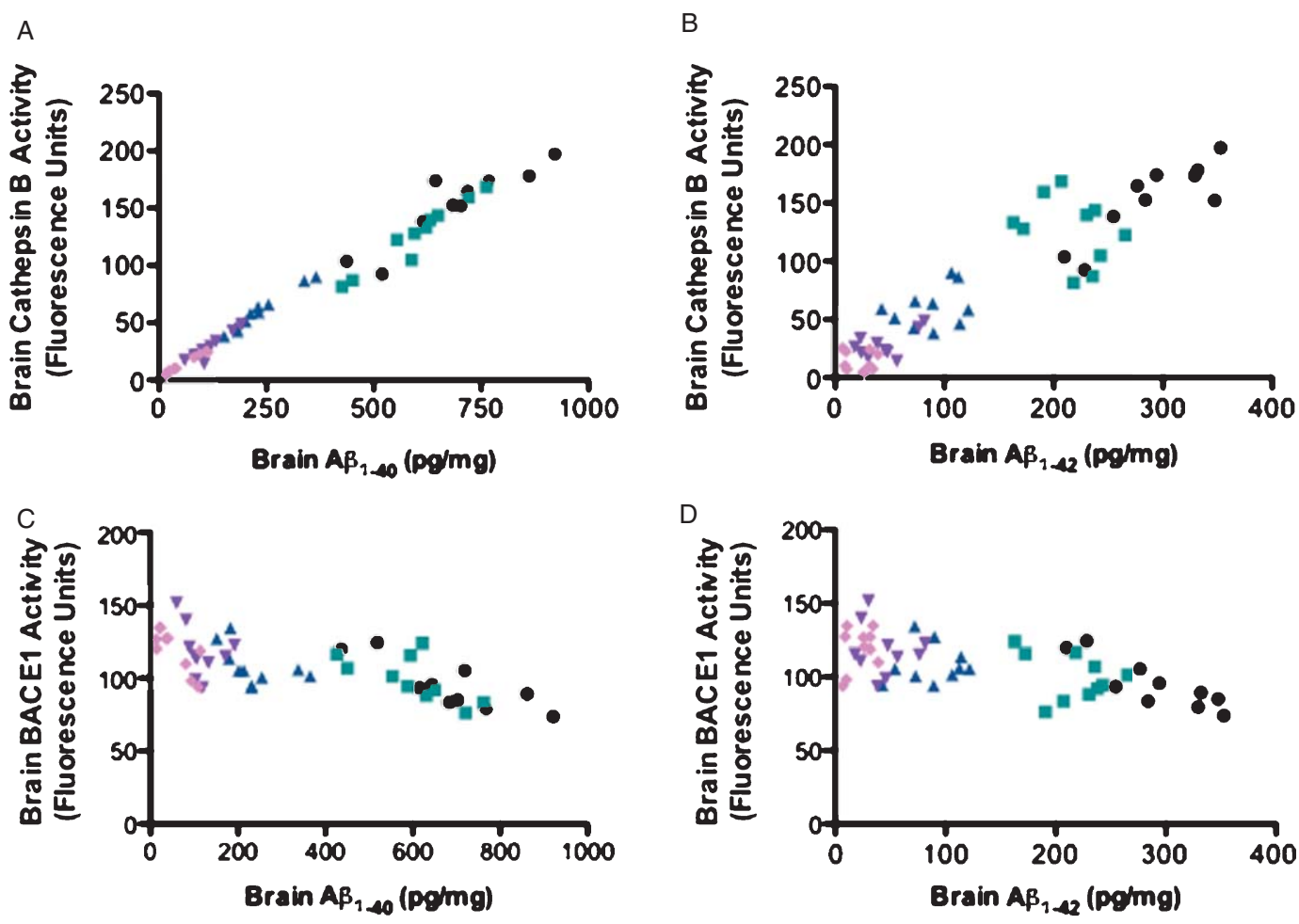

- Control (no E64d)

( $5.0 \mathrm{mg} / \mathrm{kg} / \mathrm{day} E 64 \mathrm{~d}$

- 0.1 mgkg/day E64d

$10 \mathrm{mg} / \mathrm{kg} / \mathrm{day}$ E64d

$41.0 \mathrm{mg} k \mathrm{~kg} / \mathrm{day}$ E64d

Fig. 4. Cathepsin $B$ and $A \beta$ are positively correlated, $B A C E 1$ and $A \beta$ are negatively correlated in guinea pigs. The individual paired data from all guinea pigs for brain $A \beta_{40}$ or $A \beta_{42}$ data versus brain cathepsin $B$ activity were plotted (Fig. $4 A, B$ ). Linear regression analysis for brain $A \beta_{40}$ versus brain cathepsin B activity finds a $r^{2}=0.98$ and a $95 \%$ confidence interval for a 0.21 to 0.22 slope, which is a significantly non-zero slope at $p<0.0001$. For brain $\mathrm{A} \beta_{42}$ versus brain cathepsin $\mathrm{B}$ activity, linear regression analysis of finds a $r^{2}=0.87$ and a $95 \%$ confidence interval for a 0.45 to 0.56 slope, which is a significant non-zero slope at $p<0.0001$. Thus, brain cathepsin B activity is a strong predictor of brain $A \beta$ and these data are consistent with E64d reducing brain $A \beta$ by inhibiting cathepsin B $\beta$-secretase activity. In contrast, paired data from individual guinea pigs for brain $A \beta_{40}$ or $A \beta_{42}$ vs. brain BACE1 activity at the various E64d doses shows a very weak, slightly negative correlation (Fig. $4 C$, D). Linear regression analysis of brain $\mathrm{A} \beta_{40}$ versus brain BACE1 activity finds a $r^{2}=0.45$ and a $95 \%$ confidence interval for a -0.06 to -0.03 slope, which is a significant non-zero slope at $p<0.0001$. Linear regression analysis of brain $\mathrm{A} \beta_{42}$ versus brain BACE1 activity finds $r^{2}=0.36$ and a $95 \%$ confidence interval for a -0.14 to -0.06 slope, which is a significant non-zero slope at $p<0.001$. These data show that brain BACE1 activity is not predictive of brain $\mathrm{A} \beta$ and argue against $\mathrm{E} 64 \mathrm{~d}$ reducing brain $\mathrm{A} \beta$ by inhibiting BACE1 $\beta$-secretase activity.

brain cathepsin B activity relative to controls (Fig. 7A). Thus, E64d is also clearly inhibiting cathepsin B brain activity in transgenic A $\beta P P L o n$ mice and that is consistent with the compound acting by reducing cathepsin B $\beta$-secretase activity.

\section{Mouse brain BACE1 activity}

E64d feeding for one or 3 months caused higher brain BACE1 activity in all mice, but a statistically significant increase averaging only $17 \%$ occurred in the old mice (Fig. 7B). Thus, E64d treatment increased brain BACE1 activity in the AßPPLon mice. These data rule out E64d as inhibiting brain BACE1 $\beta$ - secretase activity and thereby lowering brain $A \beta$ because brain BACE1 activity would have to decrease, not increase as was observed, for that to be the mechanism of action.

\section{Mouse memory deficits - latency period}

Feeding E64d for one or 3 months significantly improved the memory deficits of both age groups as measured by the latency period in the Morris water maze swimming test (Fig. 8A). The percent improvement in the latency period for each age group and feeding schedule is summarized in Table 3 and is an average improvement of $35 \%$. The average swimming 

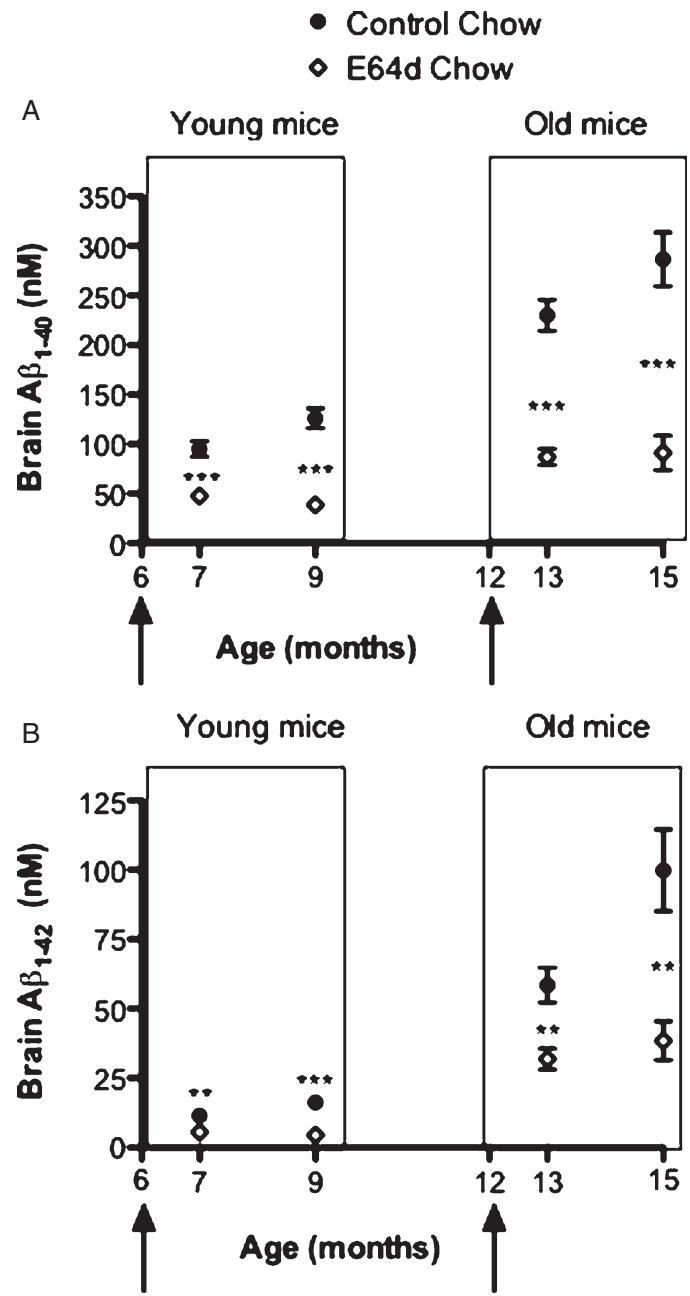

Fig. 5. Feeding E6 d chow to transgenic A $\beta P P L o n$ AD mice reduces brain $A \beta_{40}$ and $A \beta_{42}$. Brain $A \beta$ is shown as a function of the mouse age with young ( $6-9$ months of age) and old (12-15 months of age) mice boxed separately. The arrows indicate the age at which the experimental animals were switched from normal to E64d chow and fed that chow for either one or 3 months. In other words, the young animals were fed the E64d chow until they were 7 or 9 months old and the old animals were fed the E64d chow until they were 13 or 15 months old. Brain $A \beta_{40}$ was significantly reduced in both young and old mice fed for ether one or 3 months (Fig. 5A, arrows indicate age at which E64d feeding began, and Table 1). Brain $\mathrm{A} \beta_{42}$ was also significantly reduced in both young and old mice fed E64d chow for either one or 3 months (Fig. 5B and Table 2). Thus, even though brain $A \beta_{40}$ and $A \beta_{42}$ increased with increasing age in control animals, the $\mathrm{A} \beta_{40}$ and $A \beta_{42}$ in the E64d treated animals was consistently reduced at both ages and feeding schedules. Particularly significant is that E64d was efficacious at reducing $A \beta_{40}$ and $A \beta_{42}$ in the old animals even though feeding was not initiated until after those animals had accumulated abnormal levels of $A \beta_{40}$ and $A \beta_{42}$. This suggests that the compound is effective at arresting further brain $A \beta_{40}$ and $\mathrm{A} \beta_{42}$ accumulation even after abnormal levels have developed. The mean and SEM are displayed at each data point. Stars represent statistically significant differences between the means of age-matched E64d and normal chow fed mice (t-test comparison $* * * p<n=10$ animals/group).
Table 1

Brain $A \beta_{40}$ reduction in young and old transgenic $\mathrm{AD}$ mice fed E64d for one or 3 months

\begin{tabular}{lcc}
\hline Mouse Age & $\begin{array}{c}\text { E64d feeding } \\
\text { treatment } \\
\text { (months) }\end{array}$ & $\begin{array}{c}\text { Reduction in brain } \\
\mathrm{A} \beta_{40} \text { relative } \\
\text { to controls }(\%)\end{array}$ \\
\hline Young $^{+}$ & 1 & 50 \\
Young $^{+}$ & 3 & 69 \\
Old $^{\wedge}$ & 1 & 62 \\
Old $^{\wedge}$ & 3 & 68 \\
Average for all ages & & 62 \\
$\quad$ \& treatments & &
\end{tabular}

$\&$ treatments

${ }^{+}$Young mice began E64d feeding at 6 months of age; ${ }^{\wedge}$ Old mice began E64d feeding at 12 months of age.

Table 2

Brain $A \beta_{42}$ reduction in young and old transgenic $A D$ mice fed E64d for one or 3 months

\begin{tabular}{lcc}
\hline Mouse Age & $\begin{array}{c}\text { E64d feeding } \\
\text { treatment } \\
\text { (months) }\end{array}$ & $\begin{array}{c}\text { Reduction in brain } \\
\mathrm{A} \beta_{40} \text { relative } \\
\text { to controls }(\%)\end{array}$ \\
\hline Young $^{+}$ & 1 & 52 \\
Young $^{+}$ & 3 & 72 \\
Old $^{\wedge}$ & 1 & 46 \\
$\begin{array}{l}\text { Old }^{\wedge} \\
\text { Average for all ages } \\
\text { and treatments }\end{array}$ & 3 & 61 \\
\hline
\end{tabular}

${ }^{+}$Young mice began E64d feeding at 6 months of age; 'Old mice began E64d feeding at 12 months of age.

speed of the E64d treated animals did not differ from that of age-matched controls (data not shown) and thus behavioral differences are not due to differences in swimming ability. These data support the potential of oral E64d for improving memory deficits.

\section{Mouse memory deficits - distance traveled}

Feeding E64d for one or 3 months caused a significant reduction in the distance traveled in the Morris water maze test (Fig. 8B). The percent improvement in the latency period for each age group and feeding schedule is summarized in Table 4 and is an average improvement of $34 \%$. Significantly, the E64d treatment for one and 3 months resulted in a marked improvement in memory deficits for the old mice, which had already developed impairment. Again, these data support the potential of oral E64d for improving memory deficits in AD patients, possibly even after it has developed.

\section{Mouse memory retention}

In the spatial probe trial, the platform was removed from the pool and memory retention was measured by determining the percent of a 60 second time period in which the animal swam in the NE quadrant where the platform had previously been. The mice fed the E64d 
A

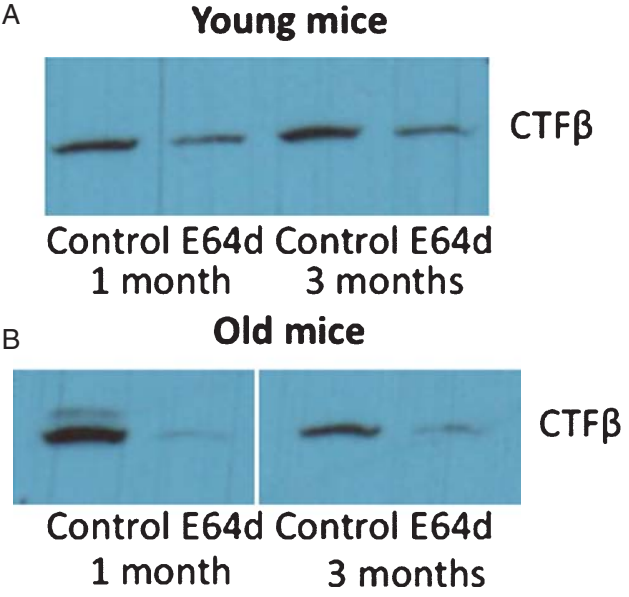

D Young mice

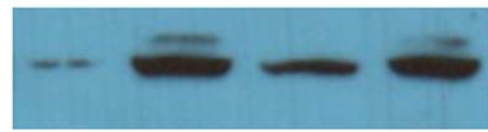

$S A B P P \alpha$
Control E64d Control E64d 1 month 3 months

$\mathrm{E}$

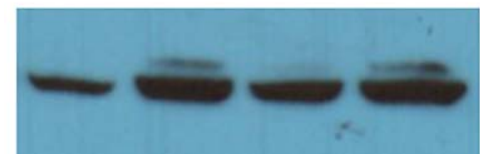

Control E64d Control E64d 1 month 3 months
C

- Control Chow

- E64d Chow
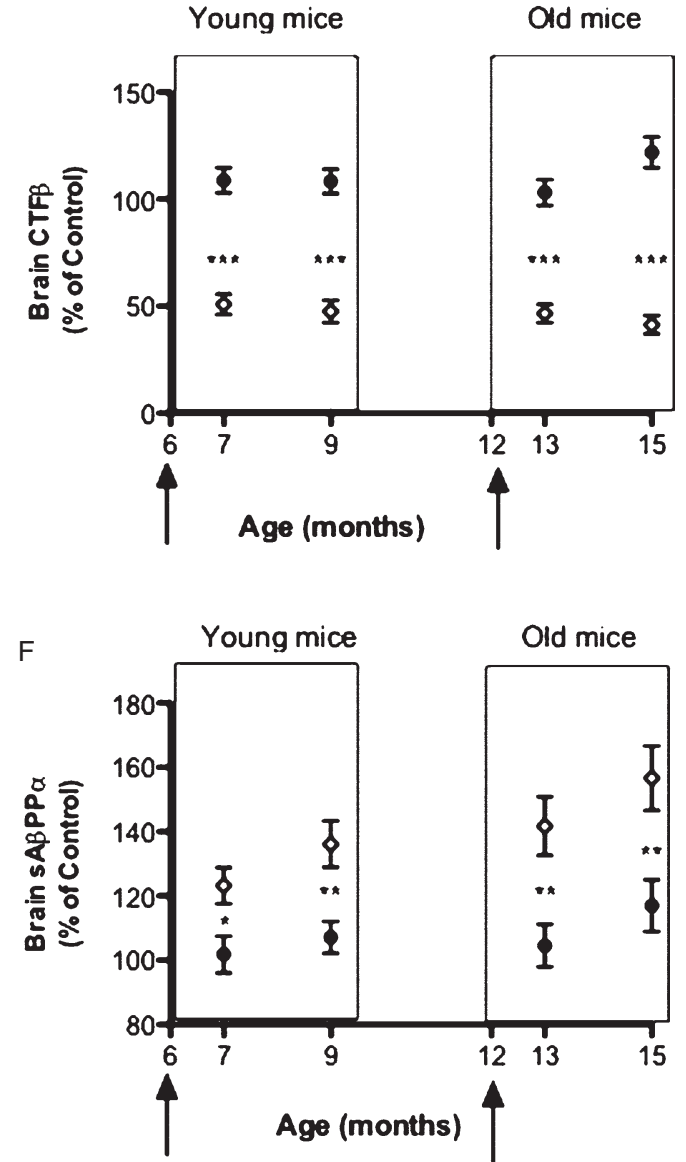

Fig. 6. Feeding E64d chow to transgenic AßPPLon AD mice decreases brain CTF $\beta$ and increases sA $\beta P P \alpha$. Western blots show that feeding E64d chow results in qualitatively less brain CTF $\beta$ than controls (Fig. 6A-C, arrows indicate the age at which E64d feeding began). Quantitative densitometry of the Western CTF $\beta$ blots shows that brain CTF $\beta$ is reduced in young and old animals fed E64d for one or 3 months by about $50 \%$ (Fig. 6 C, arrows show age at which E64d chow feeding began). As CTF $\beta$ is a proteolytic fragment of $\beta$-secretase cleavage, these data are consistent with E64d acting by inhibiting $\beta$-secretase activity. In contrast, Western blots of sA $\beta$ PP $\alpha$ qualitatively show that E64d feeding increased brain sA $\beta P P \alpha$ relative to controls (Fig. 6D-F). Quantitative densitometry of the Western sA $\beta P P \alpha$ blots shows that there is consistently more brain sA $\beta P P \alpha$ in young and old animals fed E64d for one or 3 months than in controls (Fig. 6F). Increased sA $\beta P P \alpha$ is consistent with E64d inhibiting $\beta$-secretase activity because that inhibition would allow more production of $\operatorname{sA} \beta P P \alpha$. The mean and SEM are displayed at each data point (t-test comparison ${ }^{*} p<0.02,{ }^{* *} p<0.004,{ }^{* *} p<0.0001, n=10$ animals/group).

chow spent a higher percentage of their time swimming in the NE quadrant than did the normal chow fed animals (Fig. 8C). The percentage improvement in the percentage of time spent in the NE quadrant due to E64d feeding is summarized in Table 5 and is an average $105 \%$ improvement. Thus the chow fed animals demonstrated significantly less cognitive impairment (better memory retention) as compared to control diet fed mice. These data provide support for E64d's potential to improve memory retention in AD.

\section{Mouse brain amyloid plaque}

As discussed above transgenic A $\beta P P L o n$ mice accumulate brain $A \beta$ and amyloid plaque as they age. Young mice fed either the control or E64d chow for one month (7 months old) had no brain amyloid plaque (Fig. 9). But young mice fed the control for 3 months (until they were 9 months old) had only a small amount of plaque $(0.12 \%$ area), which the E64d diet completely prevented. Consistent with previous transgenic $A \beta P P L o n$ mice studies $[25,26]$, only 


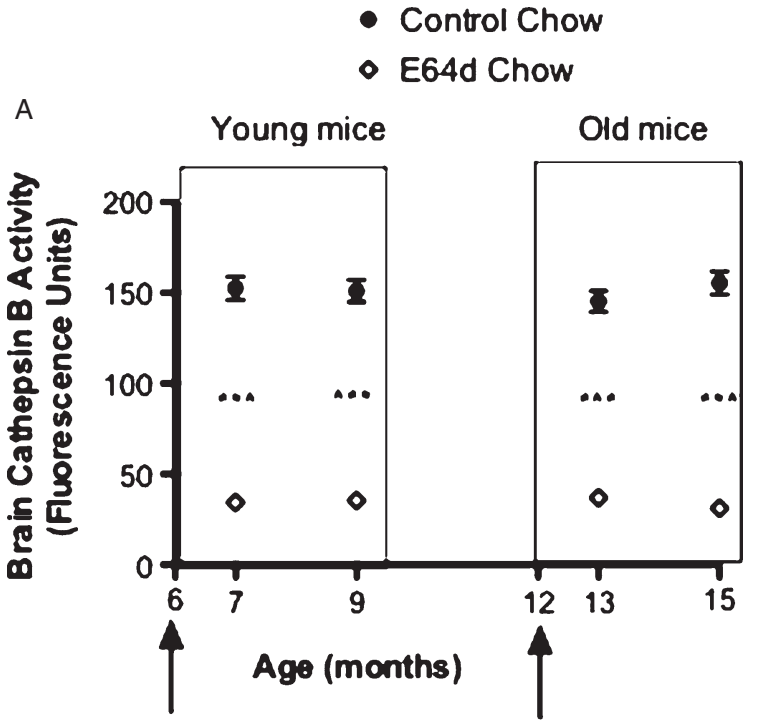

B

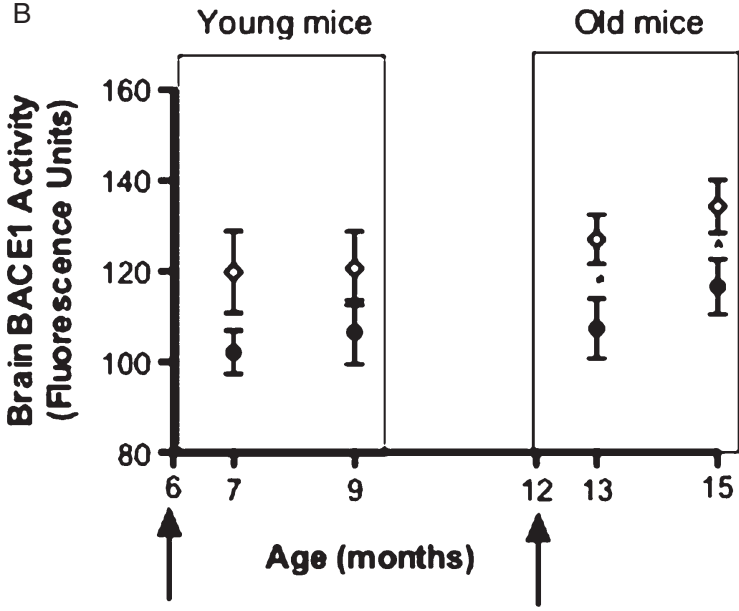

Fig. 7. Feeding E64d chow to transgenic AßPPLon AD mice reduces brain cathepsin B activity and either has no effect or increases brain BACE1 activity. Feeding E64d chow to either young or old mice for one or 3 months reduced brain cathepsin B activity by about $83 \%$ (Fig. 7A, arrows show age at which E64d chow feeding began). Brain cathepsin B inhibition is required if E64d acts by suppressing cathepsin B $\beta$-secretase activity and thus these data are consistent with the compound acting by that mechanism of drug action. In contrast, feeding E64d chow for one or 3 months to young mice increased brain BACE1 activity but the increase was not statistically significant (Fig. 7B). And feeding E64d chow for one or 3 months to old mice significantly increased brain BACE1 activity relative to animals feed normal chow by about $16 \%$. These data show that the effects of E64d on brain $A \beta$ are not due to off-target inhibition of brain BACE1 $\beta$-secretase activity because E64d treatment did not inhibit brain BACE1 activity, but, rather, increased brain BACE1 activity. The mean and SEM are displayed at each data point (t-test comparison $* p<0.04, n=10$ animals/group).

older (>12 months of age) animals had significant brain plaque. Old animals fed the control or the E64d diet for one month (until they were 13 months old) had 0.35 or $0.18 \%$ plaque areas, respectively, with the
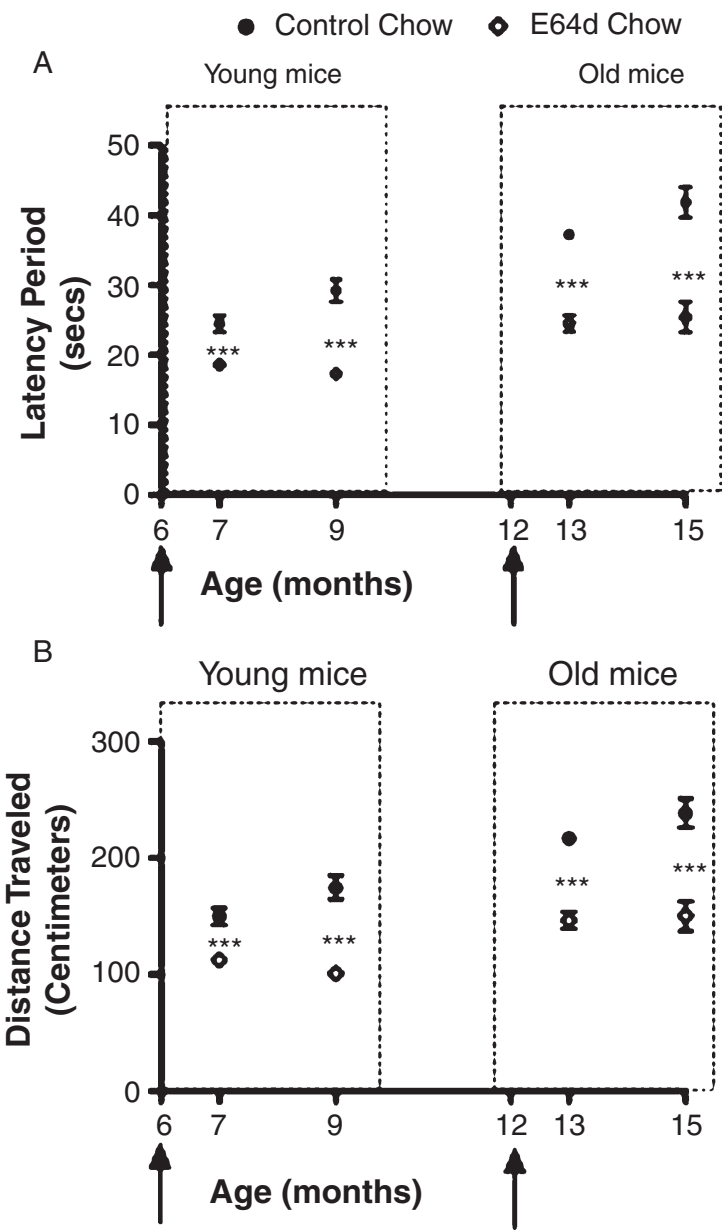

Fig. 8. Feeding E64d chow to transgenic AßPPLon AD mice improves memory deficits and memory retention. As they age, transgenic $\mathrm{A} \beta P P L$ on mice mimic the behavior of $\mathrm{AD}$ patients in that they progressively develop memory deficits, which can be assessed using the Morris water maze test by measuring the time it takes the animals to find a invisible, submerged platform (latency period) and distance traveled to find that platform. Feeding E64d chow to young ((6-9 months) or old (12-15 months of age) mice for either one or 3 months significantly improved the animals' ability to remember the location of the platform as measured by the latency period (Fig. 8A, arrows indicate age at which E64d feeding began, and Table 3). Significantly, E64d treatment improved memory deficits in 15-month-old animals, which had significant memory deficits, suggesting that the compound may be able to restore memory after a deficit has occurred. Similarly, feeding E64d chow to young or old mice for either one or 3 months reduced the distance traveled (Fig. 8B and Table 4) Again, this data shows that oral administration of E64d is able to improve memory deficits that otherwise will occur in this transgenic $\mathrm{AD}$ animal model. To test memory retention, mice were also tested for the percentage of time spent in the northeast (NE) target quadrant after the platform was removed from that quadrant (Fig. 8C and Table 5). All E64d treated groups spent more time in the target quadrant than did age-matched untreated animals showing that the E64d resulted in greater memory retention. Together, these data suggest that oral E64d administration may also be able to prevent or reverse the memory decline seen in $\mathrm{AD}$ patients. The mean and SEM are displayed at each data point ( $\mathrm{t}$ test comparison $* * * p<0.0001, n=10$ animals/group). 


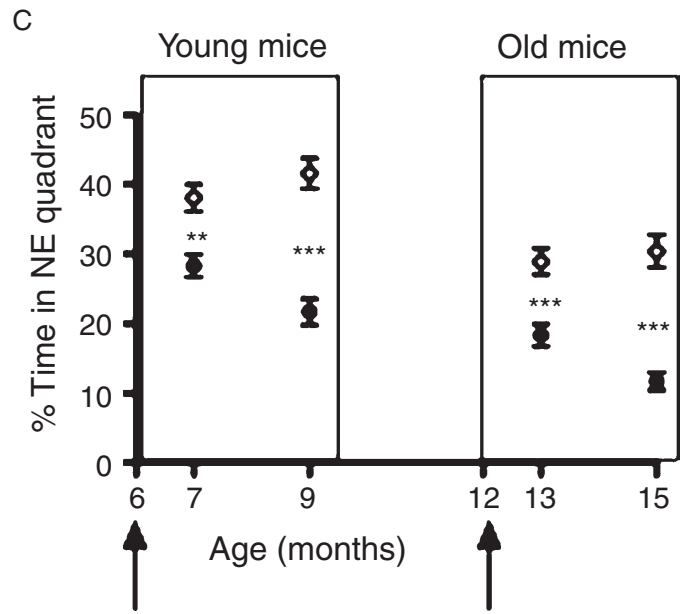

Fig. 8. (Continued)

Table 3

Improvement of memory deficits as measured by the latency period in the Morris water maze test for young and old transgenic AD mice fed E64d for one or 3 months

\begin{tabular}{lcc}
\hline Mouse Age & $\begin{array}{c}\text { E64d feeding } \\
\text { treatment } \\
\text { (months) }\end{array}$ & $\begin{array}{c}\text { Improvement in latency } \\
\text { period relative } \\
\text { to controls }(\%)\end{array}$ \\
\hline Young $^{+}$ & 1 & 25 \\
Young $^{+}$ & 3 & 41 \\
Old $^{\wedge}$ & 1 & 35 \\
Old $^{\wedge}$ & 3 & 38 \\
Average for all ages & & 35 \\
and treatments & &
\end{tabular}

${ }^{+}$Young mice began E64d feeding at 6 months of age; ^old mice began E64d feeding at 12 months of age.

one-month E64d treatment causing a 49\% reduction in brain plaque. Old animals fed the control or the E64d diet for 3 months (until they were 15 months old) had 0.68 or $0.27 \%$ plaque areas, respectively, with the 3 -month treatment causing a $60 \%$ reduction in brain plaque. Thus, the E64d treatment not only reduced brain $\mathrm{A} \beta$ but it also reduced the brain amylodid plaque load, which is a pathological hallmark of AD.

\section{Mouse latency period is positively correlated with brain $A \beta$}

Paired analyses of the latency period and brain $A \beta_{40}$ or $A \beta_{42}$ data from individual mice showed strong positive correlations (Fig. 10A-D). The one and 3-month feeding schedule data was combined and the control and treated data separately analyzed. Interestingly, in the older animals, the slope for the E64d treated animals was about 2 times steeper than that of the control for both $A \beta_{40}$ and $A \beta_{42}$. The steeper slopes for the treated animals suggest that E64d may affect other
Table 4

Improvement of memory deficits as measured by the distance traveled in the Morris water maze test for young and old transgenic AD mice fed E64d for one or 3 months

\begin{tabular}{lcc}
\hline Mouse Age & $\begin{array}{c}\text { E64d feeding } \\
\text { treatment } \\
\text { (months) }\end{array}$ & $\begin{array}{c}\text { Improvement in distance } \\
\text { traveled relative } \\
\text { to controls }(\%)\end{array}$ \\
\hline Young $^{+}$ & 1 & 25 \\
Young $^{+}$ & 3 & 42 \\
Old $^{\wedge}$ & 1 & 33 \\
Old $^{\wedge}$ & 3 & 37 \\
Average for all ages & & 34 \\
$\quad$ and treatments & &
\end{tabular}

${ }^{+}$Young mice began E64d feeding at 6 months of age; ${ }^{\wedge}$ Old mice began E64d feeding at 12 months of age.

Table 5

Improvement of memory retention as measured by the percentage of time spent in the quadrant, which had previously contained a submerged platform, for young and old transgenic AD mice fed E64d for one or 3 months

\begin{tabular}{lcc}
\hline Mouse Age & $\begin{array}{c}\text { E64d feeding } \\
\text { treatment } \\
\text { (months) }\end{array}$ & $\begin{array}{c}\text { Improvement in percentage } \\
\text { of time spent in } \\
\text { NE quadrant }(\%)\end{array}$ \\
\hline Young $^{+}$ & 1 & 35 \\
Young $^{+}$ & 3 & 91 \\
Old $^{\wedge}$ & 1 & 86 \\
Old $^{\wedge}$ & 3 & 207 \\
Average for all ages & & 105 \\
and treatments & \\
+Young mice began E64d feeding at 6 months of age; `Old mice \\
began E64d feeding at 12 months of age.
\end{tabular}

factors in addition to brain $A \beta$ and thereby improve memory.

\section{Mouse latency period is not correlated with brain amyloid plaque}

Although E64d improved memory deficits and reduced brain amyloid plaque in old mice, paired analysis of the latency period and brain amyloid plaque load from individual old mice showed no correlation for control or E64d treated animals $\left(r^{2}=0.14\right.$ and 0.01 for control and treated animals, respectively, data not shown).

\section{DISCUSSION}

A significant result of this study is that simply feeding E64d chow to transgenic A $\beta P P L o n$ mice improved the memory deficits and memory retention in these mice relative to age-matched transgenic mice fed control chow (Fig. 8). On average, young and old mice fed E64d chow for one or 3 months had about a 35\% improvement in their latency period and their distance traveled swimming to the submerged platform in the 
A
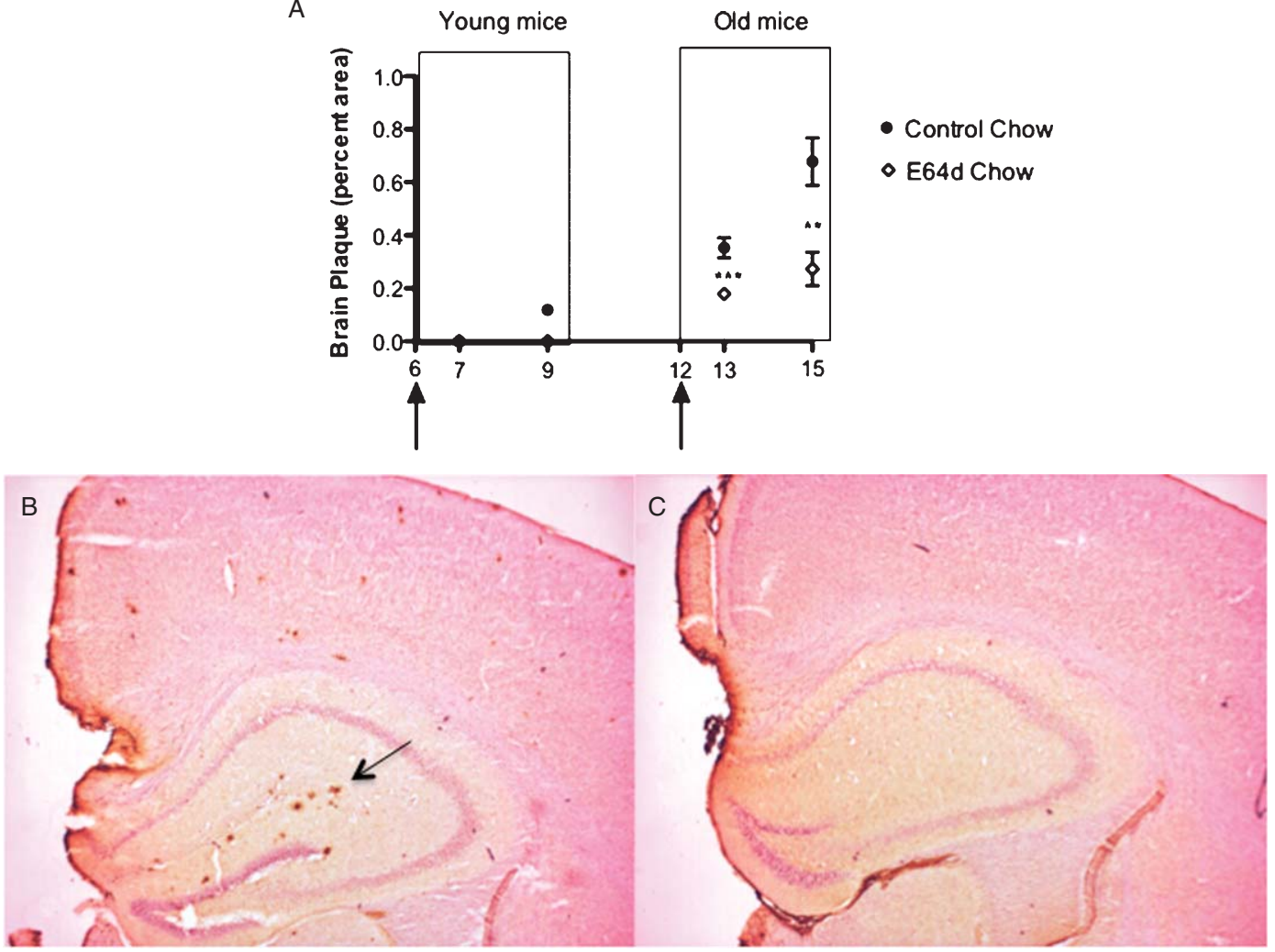

Fig. 9. E64d treatment of transgenic AßPPLon AD mice reduces brain amyloid plaque. Transgenic A $\beta P P L o n$ mice also mimic the pathology seen in $\mathrm{AD}$ patients in that they develop brain amyloid plaque as they age. Quantitative image analysis of brain sections stained for amyloid plaque in young mice show that control and treated mice have no amyloid plaque at 7 months of age and that control and E64d treated mice have very little amyloid plaque and no amyloid plaque, respectively, at 9 months of age (Fig. 9A arrows show age at which E64d chow feeding began). Quantitative image analysis of brain sections from old mice show that control mice have significant amyloid plaque at 13 and 15 months of age and that E64d significantly reduced the amyloid plaque at both ages (Fig. 9A). Histological micrographs of a brain region from a 15 month-old mouse fed control chow for 3 months shows numerous plaques, including one in the hippocampus pointed to by the arrow (Fig. 9B). A corresponding histological micrograph from a 15 month-old animal fed E64d chow for 3 months shows very little plaque (Fig. 9C). These data suggest that oral E64d administration may also be able to reduce the brain plaque seen in AD patients. The mean and SEM are displayed at each data point ( $\mathrm{t}$ test comparison ${ }^{* *} p<0.002,{ }^{* * *} p<0.0001, n=10$ animals/group).

Morris water maze test relative to animals fed control chow. These data show that the E64d improved memory deficits. Moreover, in the memory retention test in which the platform was removed, E64d fed animals spent an average $105 \%$ greater percent time in the quadrant where the platform had been relative to controls. These data show that E64d improved memory retention. Importantly, beginning E64d feeding when mice were old (12 months of age) and had already developed significant memory impairment, improved the memory deficits and memory retention relative to age-matched controls. That shows that in this model the compound retards or arrests the memory decline even after it has manifested itself. Young mice also have memory deficits, although not as severe as that in old mice, and feeding E64d to young mice beginning at
6 months of age significantly improved their memory deficits and memory retention relative to age-matched controls. Thus, the data show that oral E64d administration improves in young and old animal models the primary problem in $\mathrm{AD}$, memory decline, which suggests that the compound may have potential for treating early and late stages of $\mathrm{AD}$.

Feeding E64d to transgenic AßPPLon mice also reduces brain amyloid plaque, which develops in these animals and mimics that pathology seen in $\mathrm{AD}$ patients (Fig. 9). Feeding E64d to mice that are old and have significant brain plaque reduced the brain plaque by $49 \%$ on average relative to age-matched controls. Although the young animals had not yet manifested significant amounts of brain plaque, the small amount found in the 9 month old controls was completely absent in 

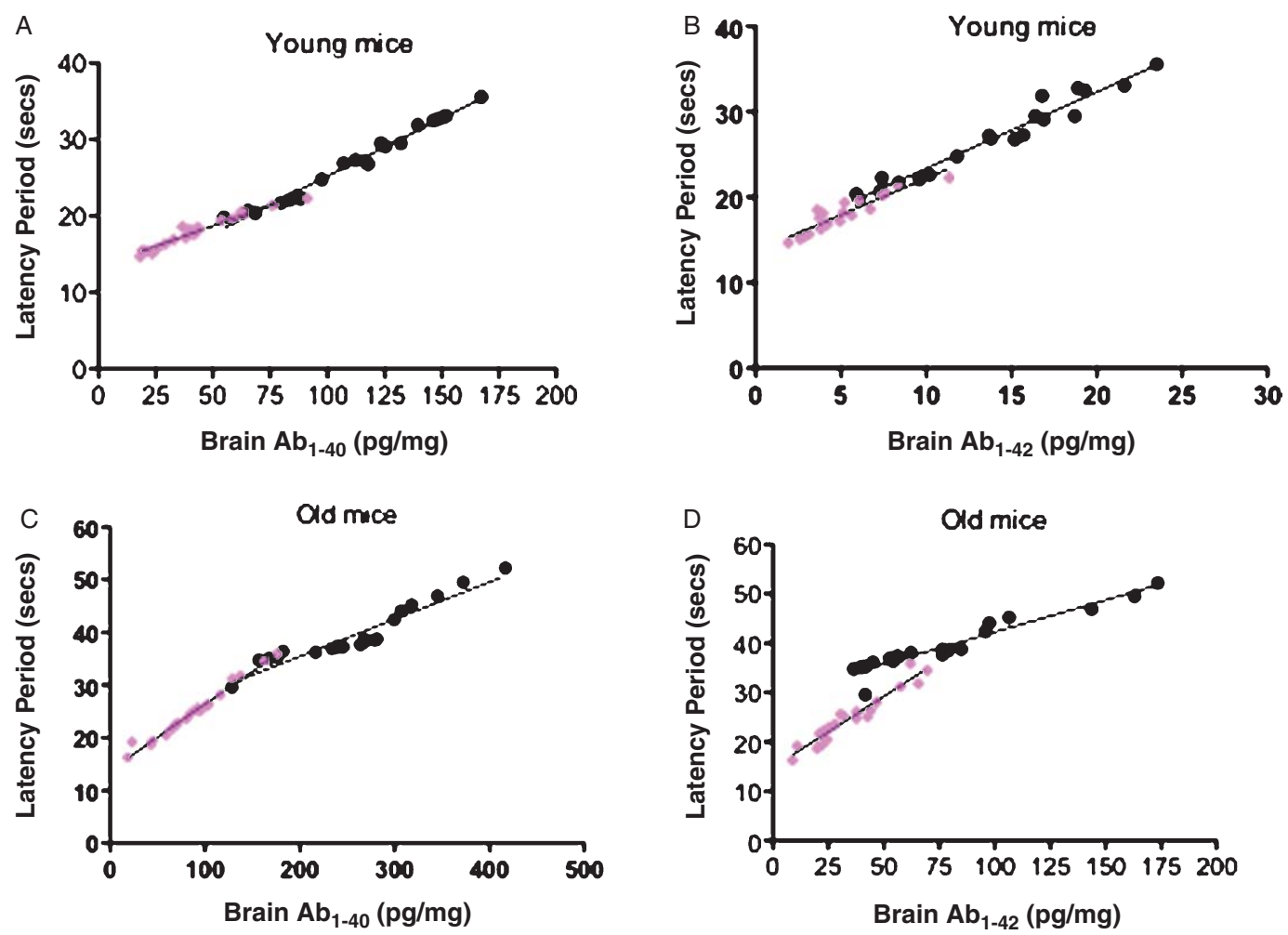

- Control chow

- E64d chow

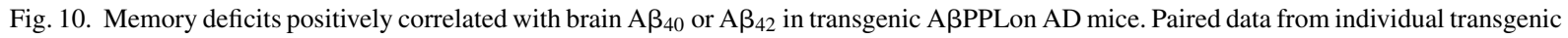
$\mathrm{A} \beta$ PPLon mice shows that the latency period obtained in the Morris water maze test is strongly, positively correlated with brain $A \beta_{40}$ or $A \beta_{42}$ for control and treated young and old mice. The treated and control data combines the one and 3 month feeding schedules. In young mice, the latency period and brain $\mathrm{A}_{40}$ is strongly positively correlated for both treated and control mice $\left(r^{2}=0.98\right)$ with similar slopes for the treated and control mice (Fig. 10A). In young mice, the latency period and brain $\mathrm{A} \beta_{42}$ is also strongly positively correlated for both treated and control mice $\left(r^{2}=0.95\right)$ with similar slopes for the treated and control mice (Fig. 10B). In old mice, the latency and brain $\mathrm{A} \beta_{40}$ is again strongly positively correlated $\left(r^{2}=0.95\right)$ but the correlation for the treated animals has a much steeper slope than that for the controls (Fig. 10 C). Similarly, the old mice show a strong positive correlation between latency period and brain $\mathrm{A}_{42}\left(r^{2}=0.95\right)$ with the treated animals having a much steeper positive slope than that of the controls (Fig. 10D). These data demonstrate that memory deficits as measured by the latency period is a function of brain $A \beta$ with more brain $A \beta$ correlated with more memory deficits. Interestingly, the steeper correlation in the old mice for the treated animals relative to controls suggests that E64d may have other memory improving effects that are in addition to that caused by lowering brain $A \beta$.

the age-matched E64d treated mice. Thus, oral E64d administration reduces a characteristic AD pathology, brain amyloid plaque, in this animal model and that also suggests E64d may have AD therapeutic potential.

The brain amyloid plaque and memory deficits observed in the transgenic A $\beta$ PPLon mice are likely due to the abnormal accumulation of brain $A \beta$ because the major difference between the transgenic A $\beta P P L o n$ mice and their non-transgenic strain matched controls is brain $A \beta$ accumulation. The brain amyloid plaque that develops in these animals is undoubtedly caused by the abnormal brain $A \beta$ accumulation because brain $\mathrm{A} \beta$ peptides are the primary component of brain amyloid plaque. In regard to the memory deficits, the fact that E64d treated animals had significantly reduced brain $A \beta$ and improved memory deficits relative to age-matched controls not fed E64d is consistent with brain $A \beta$ causing the memory deficits (Figs. 5 and 8). Furthermore, the strong positive correlation found between brain $A \beta_{40}$ and $A \beta_{42}$ and increasing memory deficits also supports this hypothesis (Fig. 10). In young mice, the correlation slopes between $A \beta_{40}$ or $A \beta_{42}$ and the latency period were about the same for E64d treated and control transgenic mice showing that the brain $\mathrm{A} \beta$ effect on memory was proportionally the same for both groups. In old mice, on the other hand, the correlation slope between the brain $A \beta_{40}$ or $A \beta_{42}$ and the latency period was significantly more positive 
for the E64d treated than for the old control transgenic mice showing that brain $A \beta$ effect on memory was not proportionally the same for both groups, which suggests that additional factor(s) may also contribute to the improved memory seen in the old animals treated with E64d. As discussed below, such additional factors may be due to the neuroprotective effects of E64d.

Another important result of this study is that oral administration of E64d to transgenic AßPPLon mice or normal guinea pigs results in an approximately equal reduction in brain $A \beta_{40}$ and $A \beta_{42}$, a concomitant reduction in brain CTF $\beta$ and an increase in brain sA $\beta P P \alpha$. In the transgenic A $\beta P P L o n$ mice, E64d treatment for all ages and treatments reduced brain $A \beta_{40}$ and $A \beta_{42}$ by about $62 \%$ and $58 \%$, respectively, brain CTF $\beta$ by about $50 \%$ and increased brain $\operatorname{sA} \beta P P \alpha$ by about $29 \%$. In guinea pigs, E64d treatment produced dose-dependent reductions in brain $A \beta_{40}$ and $A \beta_{42}$, brain CTF $\beta$ and a dose dependent increase in brain $\operatorname{sA} \beta P P \alpha$. These data agree with our previous work, which showed that icv E64d administration to either transgenic A $\beta P P L o n$ mice or normal guinea pigs also resulted in the same brain A $\beta$ peptide pattern [39-41]. That pattern is consistent with the compound reducing brain $\mathrm{A} \beta$ by lowering its production through inhibiting $\beta$-secretase activity [23]. Thus, the memory improvement combined with reduced brain $\mathrm{A} \beta$ and amyloid plaque, which occurred upon treating the transgenic A $\beta P P L o n$ mice, is likely due to a decrease in brain $A \beta$ production caused by inhibition of $\beta$-secretase activity.

But the question is which $\beta$-secretase activity is inhibited by E64d? Two proteases are currently proposed to have that activity, the aspartyl protease BACE1 and the cysteine protease cathepsin B. Deleting the BACE1 gene in transgenic mice expressing A $\beta P P$ containing the Swe $\beta$-secretase site sequence results in the characteristic peptide pattern expected of $\beta$-secretase inhibition [53], but detailed evaluation of the BACE1 gene knockout studies indicate that they do not preclude participation of cathepsin $B$ in $A \beta$ production (see review in [23]). Likewise, deleting the cathepsin $\mathrm{B}$ gene in transgenic mice expressing human wt A $\beta P P$ also results in that peptide pattern of $\beta$-secretase inhibition [36]. The data here clearly show that E64d administration caused an increase in brain BACE1 activity and a decrease in brain cathepsin $B$ activity in both the guinea pigs and the transgenic A $\beta P P L o n$ mice. BACE1 activity was slightly negatively correlated whereas brain cathepsin B activity was highly positively correlated with brain $A \beta_{40}$ or $A \beta_{42}$ versus brain $A \beta_{40}$ or $A \beta_{42}$ in guinea pigs. Thus, brain BACE1 activity had no predictive power whereas brain cathepsin $\mathrm{B}$ activity had very high predictive power for determining brain $A \beta_{40}$ or $A \beta_{42}$ levels in guinea pigs. These data are consistent with in vitro data, which has shown that E64 c has no effect on BACE1 activity but is a potent cathepsin B inhibitor [23]. Thus, the data show that E64d is not reducing brain $A \beta$ through BACE1 $\beta$-secretase inhibition but that it is likely inhibiting cathepsin B $\beta$-secretase activity.

It is not clear why E64d causes an increase in brain BACE1 activity but it may be due to a compensatory mechanism by which the brain is attempting to augment the reduced cathepsin B $\beta$-secretase by increasing BACE1 activity. But if that is the case, the compensation is ineffective with respect to $A \beta$ because E64d treatment results in significantly reduced brain $A \beta$. Much more research is needed to understand the relationship between cathepsin B and BACE1 $\beta$-secretase activity.

Both the transgenic A $\beta P P L o n$ mice and the guinea pigs express A $\beta P P$, which contain the human wt $\beta$ secretase site sequence, thus the $\beta$-secretase activity that occurs in these animal models is that found in the vast majority of $\mathrm{AD}$ patients. E64d's ability to inhibit wt $\beta$-secretase activity and thereby reduce brain $A \beta$ in these animal models suggests that E64d is likely to do so in most AD patients. Moreover, guinea pigs and AD patients express physiologically normal levels of $\mathrm{A} \beta \mathrm{PP}$ and thus the fact that E64d reduced brain $A \beta$ in guinea pigs argues that it also will have a similar effect on processing in $\mathrm{AD}$ patients.

The strong positive correlation between increasing $A \beta_{40}$ or $A \beta_{42}$ and worsening memory as measured by the latency period in the transgenic $A \beta P P L o n$ mice (Fig. 10) is similar to the positive correlation observed between $A \beta_{40}$ or $A \beta_{42}$ and cognitive decline in $A D$ patients [54]. As previously reported [25, 26], the young (6-9 months of age) transgenic A $\beta P P L o n$ mice developed memory deficits prior to the formation of significant brain amyloid plaque (Figs. 8 and 9A). Young transgenic A $\beta P P L o n$ mice are known to form soluble $A \beta$ aggregates [26], which are similar to the soluble $A \beta$ oligomer species correlated with cognitive decline in $\mathrm{AD}$ [13], and are thought to model mild cognitively impaired (MCI) patients [26]. As such, the improvement in memory deficits resulting from E64d treatment of young transgenic A $\beta P P L o n$ mice bodes well for the compound being effective at treating MCI or early stage AD. Also as previously reported $[25,26]$, the old (12-15 months of age) transgenic AßPPLon mice developed memory deficits and significant brain amyloid plaque (Figs. 8 and 9A). Our finding that amyloid plaque did not correlate with memory 
deficits in old mice is consistent with earlier AD studies, which also found very little correlation between amyloid deposits and dementia [55-57]. Nonetheless, the fact that E64d treatment improved memory deficits and reduced brain amyloid plaque, a hallmark of $\mathrm{AD}$, in old animals, suggests that the compound may be effective for advanced AD. Moreover, the brain amyloid plaque in old transgenic A $\beta P P L o n$ mice is known to contain post-translationally modified $A \beta$ forms called pyroglutamate $A \beta$ (pyroGluA $\beta$ )[26], which may be critical in late stage disease development [58] because they are highly neurotoxic [59], greatly accelerate $A \beta$ aggregation $[60,61]$, and are much more prevalent in AD brain than age-matched controls [62]. Thus, E64d may be able to reduce amyloid plaque containing the particularly pernicious pyroGluA $\beta$ form found in $\mathrm{AD}$ brain. Together, the data support the possibility that E64d may be successful in treating MCI or advanced AD patients.

On the other hand, treating transgenic mice expressing A $\beta P P$ containing the Swe mutant $\beta$-secretase site sequence with E64d or E64 has no effect on brain $\mathrm{A} \beta$ or CTF $\beta$ levels $[41,63]$. This is consistent with data showing that deleting the cathepsin $\mathrm{B}$ gene from transgenic mice expressing A $\beta P P$ containing the Swe $\beta$-secretase site sequence has no effect on brain $A \beta$ levels, total $A \beta$, or CTF $\beta[36,64]$. The lack of effect is likely due to the fact that cathepsin B does not cleave the Swe $\beta$-secretase site sequence to produce $A \beta$ and thus inhibiting cathepsin B activity or deleting the cathepsin $B$ gene does not reduce brain $A \beta$ or

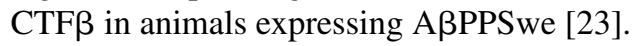

The ability to inhibit other cysteine proteases in addition to cathepsin B provides the E64 family of compounds the added advantage of also being potent neuroprotectants. For example, as discussed above, chronic E64 injection (ip) improved memory deficits in an $\mathrm{AD}$ transgenic $\mathrm{A} \beta \mathrm{PPS}$ we mouse model relative to controls even though brain $A \beta$ levels were not effected [63]. This memory improvement was attributed to E64's inhibition of calpain, another cysteine protease. Increased $A \beta$ causes increased calpain activity, which causes synaptic dysfunction and, thus, E64 is thought to reduce the synaptic dysfunction and thereby improve memory deficits by inhibiting calpain activity. AD results in widespread brain calpain activation and has long been considered a molecular basis of AD [65]. E64d and E64 c have also been shown to have significant neuroprotective effects in ischemic primate and rat models, with up to about $84 \%$ of the CA1 hippocampal neurons being retained upon treatment relative to ischemic controls [66-69]. In these mod- els, the neuroprotective effect is attributed to E64 c inhibiting cathepsin $\mathrm{B}$ and $\mathrm{L}$, which is another cysteine protease. Thus, the fact that E64d inhibits a range of cysteine proteases may be advantageous in treating AD patients by providing neuroprotection.

Another mechanism by which E64d is likely to cause neuroprotection is by increasing brain $\operatorname{sA} \beta P P \alpha$. Increasing $\mathrm{sA} \beta \mathrm{PP} \alpha$ is generally beneficial to neurons since its administration to mice and rats enhances learning and memory $[14,15]$. Thus, the increased brain $\mathrm{sA} \beta \mathrm{PP} \alpha$ caused by oral E64d demonstrated here or by icv administration as previously shown [40, 41] also likely confers neuroprotection.

The neuroprotective effects may explain why in old AßPPLon mice E64d administration improved memory deficits more than could be attributed to brain $\mathrm{A} \beta$ lowering alone. In most $\mathrm{AD}$ patients who express A $\beta P P$ containing the wt $\beta$-secretase site sequence, E64d may have multiple beneficial effects by both lowering toxic brain $A \beta$ levels and by providing neuroprotection against that toxicity.

However, one report speculated that cathepsin B may be important for the extracellular degradation of brain $A \beta$ in vivo and that inhibiting cathepsin $B$ may increase brain $A \beta$ and thereby promote memory loss and $\mathrm{AD}$ [64]. That hypothesis was based in large part on data showing that doubling brain cathepsin B activity by injecting a lenti-cathepsin B vector into the brains of transgenic A $\beta P P S w e$ mice reduced brain plaque in the area receiving the injection. The data reported here argue against that hypothesis because E64d inhibited brain cathepsin B activity and reduced brain $A \beta$ in two animal models, as well as improved memory deficits and reduced brain amyloid plaque in the transgenic A $\beta$ PPLon model. Any inhibiton of cathepsin B's ability to degrade $A \beta$ that may have occurred due to E64d administration was simply not significant because brain $A \beta$ decreased. Moreover, our previous data showed that deleting the cathepsin $\mathrm{B}$ gene in transgenic mice expressing human $A \beta P P w t$ reduces brain $A \beta[36]$. These data also are contrary to the hypothesis that inhibiting cathepsin $\mathrm{B}$ may increase brain $A \beta$ because brain $A \beta$ decreased upon completely eliminating brain cathepsin B activity. The data of this study and the knockout data can be explained by the fact that the animal models used in those experiments expressed A $\beta P P$ containing wt $\beta$ secretase site sequence, which cathepsin $B \beta$-secretase activity cleaves to produce brain $A \beta$. Thus, chemically inhibiting cathepsin B activity or ablating the cathepsin $B$ gene in such animals reduces brain $A \beta$ production, making $A \beta$ degradation unnecessary because 
brain $\mathrm{A} \beta$ need not be degraded if it is not produced. But even when cathepsin $\mathrm{B}$ inhibition does not reduce brain $A \beta$, cathepsin $B$ inhibition probably does not significantly impact the degradation of brain $A \beta$. As discussed above, chronic E64 treatment of transgenic A $\beta P P S w e$ mice had no effect on brain $A \beta$ levels but did improve memory deficits [63]. If cathepsin B degradation of $A \beta$ is significant in vivo, E64 treatment would be predicted to increase brain $A \beta$ and worsen memory deficits because E64 is a potent cathepsin B inhibitor. But since that did not occur, these data too do not support the hypothesis. While it may be that inducing viral over expression of cathepsin B can reduce brain plaque under certain conditions, the in vivo inhibitor reported here do not support the conjecture that cathepsin B inhibition would so reduce brain $\mathrm{A} \beta$ degradation that brain $A \beta$ levels would increase and memory would worsen. On the contrary, the data presented here show that inhibiting brain cathepsin B activity reduces brain $\mathrm{A} \beta$ and brain plaque and improves memory deficits.

Studies in human AD brains support a role for cathepsin B in the "disease situation." Cathepsin B is colocalized with $\mathrm{A} \beta$ in amyloid plaques of $\mathrm{AD}$ brains [70-72] and age-related changes in cathepsin $\mathrm{B}$ are consistent with the late age of onset of $\mathrm{AD}[73,74]$. Proteomic analysis of $\mathrm{AD}$ and age-matched controls showed AD patients have significantly higher CSF cathepsin B precursor levels [75] and higher plasma cathepsin B levels [76]. These findings indicate a role for cathepsin $\mathrm{B}$ in $\mathrm{AD}$.

Cathepsin B belongs to the $\mathrm{C} 1$ (papain) family of CA clan consisting of 11 human cysteine proteases $[43,77,78]$. The normal and pathological roles of cysteine cathepsins have been recently reviewed [79]. The cathepsins B, C, F, H, L, O, and $\mathrm{Z}$ are ubiquitously but differentially expressed in mammalian tissues, whereas cathepsin $\mathrm{K}$ is mainly found in osteosclasts and cathepsin $\mathrm{S}$ is in peripheral antigen-presenting cells [80]. Traditionally, cysteine cathepsins function as lysosomal proteases for protein degradation. However, they also have other intra- and extracellular functions, many of which have been revealed by gene-knockout studies (see review [78]). Cysteine proteases activate proenzymes and prohormones, mediate MHC-II-mediated antigen presentation, remodel bone, differentiate keratinocytes, regulate hair growth, and control apoptosis. They also participate in tumor metastasis, inflammatory rheumatoid arthritis, arthritis, athererosclerosis and periodontitis. Cathepsin B is a lysosomal protease but is also found in regulated secretory vesicles of chromaffin cells that produce $A \beta$ peptides [35] and secretory vesicles of pancre- atic beta-cells [81]. In brain, cathepsin B, as well as several cysteine cathepsins, show differences in neuroanatomical distribution [72, 82]. Cathepsin B deficient (non-transgenic) mice appear normal and cannot be distinguished from their wild-type counterparts [83] but have reduced trypsinogen activation in experimental pancreatitis, reduced tumor necrosis factor- $\alpha$ induced apoptosis, delayed mammary cancer and reduced tumor vascularization and growth [79].

Surprisingly, despite inhibiting this spectrum of proteases, E64d has been shown to be safe in man. E64d was originally developed by the Japanese Ministry of Health, which called it EST, in the $1980 \mathrm{~s}$ to treat muscular dystrophy and EST completed Phase III trials but did not become a drug due to a lack of sufficient efficacy for that disease [84]. Nonetheless, extensive pharmacokinetic, adsorption, metabolism, distribution, elimination, toxicology, and clinical data on EST were published in peer-reviewed Japanese journals. The details of that data cannot be fully discussed here, but in summary, they show that the compound has good oral bioavailability, a very wide therapeutic window [85-88], is safe for clinical use and was chronically administered to pediatric patients [89-92]. The low toxicity and safe clinical use may be due to the compound attenuating, but not eliminating, protease activity. Nonetheless, the safe use of E64d plus the oral efficacy demonstrated here in AD animal models gives E64d real potential as a candidate for subsequent $\mathrm{AD}$ clinical trials.

In conclusion, this study shows that oral administration of the cysteine protease inhibitor, E64d, to transgenic A $\beta P P L o n$ mice improves the memory deficits, with reduction of brain $A \beta$ peptides and amyloid plaque, that develop in this $\mathrm{AD}$ model and mimics that seen in AD patients. These effects are likely due, in large part, to E64d's ability to reduce brain $A \beta$. In transgenic $A \beta P P L o n$ mice and guinea pigs, oral E64d administration reduces brain $A \beta_{40}, A \beta_{42}, C T F \beta$, and cathepsin $\mathrm{B}$ activity while increasing brain $\mathrm{sA} \beta \mathrm{PP} \alpha$ and BACE1 activity, which is consistent with the compound reducing brain $A \beta$ production by inhibiting cathepsin $\mathrm{B}$, and not $\mathrm{BACE} 1, \beta$-secretase activity. Because E64d reduces brain $A \beta$ in animal models having the wt $\beta$-secretase activity, it is likely to also do so in most AD patients, who also have that activity. Independent of its $A \beta$ lowering effect, E64d has also been shown to be a potent neuroprotectant in $\mathrm{AD}$ and thus can be expected to provide that benefit in treating $\mathrm{AD}$ as well. Finally, the fact that the compound is orally efficacious in AD animal models and is clini- 
cally safe to use makes E64d an excellent candidate for advancement to clinical AD trials.

\section{ACKNOWLEDGMENTS}

We thank Drs. M.D. Pierschbacher and Danny Levin for their review of the manuscript. This work was supported by grant Nos. R21AG0311963, R44AG030865, and R44AG032784 from the National Institute on Aging, National Institutes of Health, Bethesda, MD, and grant No. 20100304 from the Alzheimer's Drug Discovery Foundation, New York City, NY to American Life Science Pharmaceuticals (ALSP). Dr. Gregory Hook is an employee and has equity in ALSP. Professor Vivian Hook is the Chairperson of ALSP's Scientific Advisory Board and holds equity in ALSP and that relationship has been disclosed to the University of California, San Diego, which is managing that relationship. Professor Mark Kindy is affiliated with Applied Neurotechnology, Inc. and holds equity in the company and the relationship has been disclosed to the Medical University of South Carolina, which is managing the relationship.

Authors' disclosures available online (http://www.jalz.com/disclosures/view.php?id=853).

\section{REFERENCES}

[1] Sisodia SS (1999) Alzheimer's disease: perspectives for the new millennium. J Clin Invest 104, 1169-1170.

[2] Selkoe DJ (2001) Alzheimer's disease: genes, proteins, and therapy. Physiol Rev 81, 741-766.

[3] Gandy S, Martins RN, Buxbaum J (2003) Molecular and cellular basis for anti-amyloid therapy in Alzheimer disease. Alzheimer Dis Assoc Disord 17, 259-266.

[4] McGowan E, Eriksen J, Hutton M (2006) A decade of modeling Alzheimer's disease in transgenic mice. Trends Genet 22, 281-289.

[5] Dodart JC, Mathis C, Bales KR, Paul SM (2002) Does my mouse have Alzheimer's disease? Genes Brain Behav 1, 142155.

[6] van Leuven F (2000) Single and multiple transgenic mice as models for Alzheimer's disease. Prog Neurobiol 61, 305-312.

[7] Dewachter I, Van Leuven F (2002) Secretases as targets for the treatment of Alzheimer's disease: the prospects. Lancet Neurol 1, 409-416.

[8] Turner RS (2006) Alzheimer's disease. Semin Neurol 26, 499506.

[9] Thinakaran G, Koo EH (2008) Amyloid precursor protein trafficking, processing, and function. J Biol Chem 283, 2961529619.

[10] Chow VW, Mattson MP, Wong PC, Gleichmann M (2010) An overview of APP processing enzymes and products. Neuromolecular Med 12, 1-12.
[11] Kawahara M (2010) Neurotoxicity of beta-amyloid protein: oligomerization, channel formation, and calcium dyshomeostasis. Curr Pharm Des 16, 2779-2789.

[12] Crews L, Masliah E (2010) Molecular mechanisms of neurodegeneration in Alzheimer's disease. Hum Mol Genet 19, R12-R20.

[13] Tomic JL, Pensalfini A, Head E, Glabe CG (2009) Soluble fibrillar oligomer levels are elevated in Alzheimer's disease brain and correlate with cognitive dysfunction. Neurobiol Dis 35, 352-358.

[14] Meziane H, Dodart JC, Mathis C, Little S, Clemens J, Paul SM, Ungerer A (1998) Memory-enhancing effects of secreted forms of the beta-amyloid precursor protein in normal and amnestic mice. Proc Natl Acad Sci U S A 95, 12683-12688.

[15] Taylor CJ, Ireland DR, Ballagh I, Bourne K, Marechal NM, Turner PR, Bilkey DK, Tate WP, Abraham WC (2008) Endogenous secreted amyloid precursor protein-alpha regulates hippocampal NMDA receptor function, long-term potentiation and spatial memory. Neurobiol Dis 31, 250-260.

[16] Blennow K, de Leon MJ, Zetterberg H (2006) Alzheimer's disease. Lancet 368, 387-403.

[17] Johnstone EM, Chaney MO, Norris FH, Pascual R, Little SP (1991) Conservation of the sequence of the Alzheimer's disease amyloid peptide in dog, polar bear and five other mammals by cross-species polymerase chain reaction analysis. Brain Res Mol Brain Res 10, 299-305.

[18] Beck M, Muller D, Bigl V (1997) Amyloid precursor protein in guinea pigs-complete cDNA sequence and alternative splicing. Biochim Biophys Acta 1351, 17-21.

[19] Beck M, Bigl V, Rossner S (2003) Guinea pigs as a nontransgenic model for APP processing in vitro and in vivo. Neurochem Res 28, 637-644.

[20] Ashe KH, Zahs KR (2010) Probing the biology of Alzheimer's disease in mice. Neuron 66, 631-645.

[21] Hsiao K, Chapman P, Nilsen S, Eckman C, Harigaya Y, Younkin S, Yang F, Cole G (1996) Correlative memory deficits, Abeta elevation, and amyloid plaques in transgenic mice. Science 274, 99-102.

[22] Mullan M, Crawford F, Axelman K, Houlden H, Lilius L, Winblad B, Lannfelt L (1992) A pathogenic mutation for probable Alzheimer's disease in the APP gene at the Nterminus of beta-amyloid. Nat Genet 1, 345-347.

[23] Hook V, Hook G, Kindy M (2010) Pharmacogenetic features of cathepsin B inhibitors that improve memory deficit and reduce beta-amyloid related to Alzheimer's disease. Biological Chemistry 391, 861-872.

[24] Cairns NJ, Chadwick A, Lantos PL, Levy R, Rossor MN (1993) Beta A4 protein deposition in familial Alzheimer's disease with the mutation in codon 717 of the beta A4 amyloid precursor protein gene and sporadic Alzheimer's disease. Neurosci Lett 149, 137-140.

[25] Moechars D, Dewachter I, Lorent K, Reverse D, Baekelandt V, Naidu A, Tesseur I, Spittaels K, Haute CV, Checler F, Godaux E, Cordell B, Van Leuven F (1999) Early phenotypic changes in transgenic mice that overexpress different mutants of amyloid precursor protein in brain. $\mathrm{J}$ Biol Chem 274, 6483-6492.

[26] Tanghe A, Termont A, Merchiers P, Schilling S, Demuth HU, Scrocchi L, Van Leuven F, Griffioen G, Van Dooren T (2010) Pathological hallmarks, clinical parallels, and value for drug testing in Alzheimer's disease of the APP[V717I] London Transgenic mouse model. Int J Alzheimers Dis 2010.

[27] Hussain I, Powell D, Howlett DR, Tew DG, Meek TD, Chapman C, Gloger IS, Murphy KE, Southan CD, Ryan DM, Smith TS, Simmons DL, Walsh FS, Dingwall C, Christie G 
(1999) Identification of a novel aspartic protease (Asp 2) as beta-secretase. Mol Cell Neurosci 14, 419-427.

[28] Sinha S, Lieberburg I (1999) Cellular mechanisms of betaamyloid production and secretion. Proc Natl Acad Sci U S A 96, 11049-11053.

[29] Vassar R, Bennett BD, Babu-Khan S, Kahn S, Mendiaz EA, Denis P, Teplow DB, Ross S, Amarante P, Loeloff R, Luo Y, Fisher S, Fuller J, Edenson S, Lile J, Jarosinski MA, Biere AL, Curran E, Burgess T, Louis JC, Collins F, Treanor J, Rogers G, Citron M (1999) Beta-secretase cleavage of Alzheimer's amyloid precursor protein by the transmembrane aspartic protease BACE. Science 286, 735-741.

[30] Yan R, Bienkowski MJ, Shuck ME, Miao H, Tory MC, Pauley AM, Brashier JR, Stratman NC, Mathews WR, Buhl AE, Carter DB, Tomasselli AG, Parodi LA, Heinrikson RL, Gurney ME (1999) Membrane-anchored aspartyl protease with Alzheimer's disease beta-secretase activity. Nature 402, 533537.

[31] Lin X, Koelsch G, Wu S, Downs D, Dashti A, Tang J (2000) Human aspartic protease memapsin 2 cleaves the betasecretase site of beta-amyloid precursor protein. Proc Natl Acad Sci U S A 97, 1456-1460.

[32] Gruninger-Leitch F, Schlatter D, Kung E, Nelbock P, Dobeli $\mathrm{H}$ (2002) Substrate and inhibitor profile of BACE (betasecretase) and comparison with other mammalian aspartic proteases. J Biol Chem 277, 4687-4693.

[33] Shi XP, Chen E, Yin KC, Na S, Garsky VM, Lai MT, Li YM, Platchek M, Register RB, Sardana MK, Tang MJ, Thiebeau J, Wood T, Shafer JA, Gardell SJ (2001) The pro domain of beta-secretase does not confer strict zymogen-like properties but does assist proper folding of the protease domain. J Biol Chem 276, 10366-10373.

[34] Schechter I, Ziv E (2008) Kinetic properties of cathepsin D and BACE 1 indicate the need to search for additional betasecretase candidate(s). Biol Chem 389, 313-320.

[35] Hook V, Toneff T, Bogyo M, Medzihradszky K, F., Nevenu J, Lane W, Hook G, Reisine T (2005) Inhibition of cathepsin $B$ reduces $\beta$-amyloid production in regulated secretory vesicles of neuronal chromaffin cells: evidence for cathepsin B as a candidate $\beta$-secretase of Alzheimer's disease Biological Chemistry 386, 931-940.

[36] Hook VY, Kindy M, Reinheckel T, Peters C, Hook G (2009) Genetic cathepsin B deficiency reduces beta-amyloid in transgenic mice expressing human wild-type amyloid precursor protein. Biochem Biophys Res Commun 386, 284-288.

[37] Hook VY, Kindy M, Hook G (2008) Inhibitors of cathepsin $\mathrm{B}$ improve memory and reduce beta-amyloid in transgenic Alzheimer disease mice expressing the wild-type, but not the Swedish mutant, beta-secretase site of the amyloid precursor protein. J Biol Chem 283, 7745-7753.

[38] Klein DM, Felsenstein KM, Brenneman DE (2009) Cathepsins $B$ and $L$ differentially regulate amyloid precursor protein processing. J Pharmacol Exp Ther 328, 813-821.

[39] Hook G, Hook VY, Kindy M (2007) Cysteine protease inhibitors reduce brain beta-amyloid and beta-secretase activity in vivo and are potential Alzheimer's disease therapeutics. Biol Chem 388, 979-983.

[40] Hook V, Kindy M, Hook G (2007) Cysteine protease inhibitors effectively reduce in vivo levels of brain betaamyloid related to Alzheimer's disease. Biol Chem 388, 247-252.

[41] Hook VY, Kindy M, Hook G (2008) Inhibitors of cathepsin B improve memory and reduce Abeta in transgenic Alzheimer's Disease mice expressing the wild-type, but not the Swedish mutant, beta -secretase APP site. J Biol Chem 283, 7745-7753.
[42] Tamai M, Matsumoto K, Omura S, Koyama I, Ozawa Y, Hanada K (1986) In vitro and in vivo inhibition of cysteine proteinases by EST, a new analog of E-64. J Pharmacobiodyn 9, 672-677.

[43] Barrett A, Rawlings N, Woessner J (2004) Handbook of Proteolytic Enzymes Elsevier Academic Press, pp. 1079-1113.

[44] Sadaghiani AM, Verhelst SH, Gocheva V, Hill K, Majerova E, Stinson S, Joyce JA, Bogyo M (2007) Design, synthesis, and evaluation of in vivo potency and selectivity of epoxysuccinylbased inhibitors of papain-family cysteine proteases. Chem Biol 14, 499-511.

[45] Wang KK, Yuen PW (1994) Calpain inhibition: an overview of its therapeutic potential. Trends Pharmacol Sci 15, 412-419.

[46] Tamai M, Yokoo C, Murata M, Oguma K, Sota K, Sato E, Kanaoka Y (1987) Efficient synthetic method for ethyl (+)-(2 S,3 S)-3-[(S)-3-methyl- 1-(3methylbutylcarbamoyl)butylcarbamoyl]-2-oxiranecarb oxylate (EST), a new inhibitor of cysteine proteinases. Chem Pharm Bull (Tokyo) 35, 1098-1104.

[47] Caroni P (1997) Overexpression of growth-associated proteins in the neurons of adult transgenic mice. $J$ Neurosci Methods 71, 3-9.

[48] Morris R (1984) Developments of a water-maze procedure for studying spatial learning in the rat. J Neurosci Methods 11, 47-60.

[49] Liang KC, Hon W, Tyan YM, Liao WL (1994) Involvement of hippocampal NMDA and AMPA receptors in acquisition, formation and retrieval of spatial memory in the Morris water maze. Chin J Physiol 37, 201-212.

[50] Noble JE, Bailey MJ (2009) Quantitation of protein. Methods Enzymol 463, 73-95.

[51] Deane R, Du Yan S, Submamaryan RK, LaRue B, Jovanovic S, Hogg E, Welch D, Manness L, Lin C, Yu J, Zhu H, Ghiso J, Frangione B, Stern A, Schmidt AM, Armstrong DL, Arnold B, Liliensiek B, Nawroth P, Hofman F, Kindy M, Stern D, Zlokovic B (2003) RAGE mediates amyloid-beta peptide transport across the blood-brain barrier and accumulation in brain. Nat Med 9, 907-913.

[52] Marr RA, Guan H, Rockenstein E, Kindy M, Gage FH, Verma I, Masliah E, Hersh LB (2004) Neprilysin regulates amyloid Beta peptide levels. J Mol Neurosci 22, 5-11.

[53] Luo Y, Bolon B, Kahn S, Bennett BD, Babu-Khan S, Denis P, Fan W, Kha H, Zhang J, Gong Y, Martin L, Louis JC, Yan Q, Richards WG, Citron M, Vassar R (2001) Mice deficient in BACE1, the Alzheimer's beta-secretase, have normal phenotype and abolished beta-amyloid generation. Nat Neurosci 4, 231-232.

[54] Naslund J, Haroutunian V, Mohs R, Davis KL, Davies P, Greengard P, Buxbaum JD (2000) Correlation between elevated levels of amyloid beta-peptide in the brain and cognitive decline. JAMA 283, 1571-1577.

[55] Terry RD, Masliah E, Salmon DP, Butters N, DeTeresa R, Hill R, Hansen LA, Katzman R (1991) Physical basis of cognitive alterations in Alzheimer's disease: synapse loss is the major correlate of cognitive impairment. Ann Neurol 30, 572-580.

[56] Arriagada PV, Growdon JH, Hedley-Whyte ET, Hyman BT (1992) Neurofibrillary tangles but not senile plaques parallel duration and severity of Alzheimer's disease. Neurology 42, 631-639.

[57] Berg L, McKeel DW Jr, Miller JP, Baty J, Morris JC (1993) Neuropathological indexes of Alzheimer's disease in demented and nondemented persons aged 80 years and older. Arch Neurol 50, 349-358.

[58] Schilling S, Zeitschel U, Hoffmann T, Heiser U, Francke M, Kehlen A, Holzer M, Hutter-Paier B, Prokesch M, Windisch 
M, Jagla W, Schlenzig D, Lindner C, Rudolph T, Reuter G, Cynis H, Montag D, Demuth HU, Rossner S (2008) Glutaminyl cyclase inhibition attenuates pyroglutamate Abeta and Alzheimer's disease-like pathology. Nat Med 14, 11061111.

[59] Russo C, Violani E, Salis S, Venezia V, Dolcini V, Damonte G, Benatti U, D'Arrigo C, Patrone E, Carlo P, Schettini G (2002) Pyroglutamate-modified amyloid beta-peptidesAbetaN3(pE)-strongly affect cultured neuron and astrocyte survival. J Neurochem 82, 1480-1489.

[60] Schilling S, Lauber T, Schaupp M, Manhart S, Scheel E, Bohm G, Demuth HU (2006) On the seeding and oligomerization of pGlu-amyloid peptides (in vitro). Biochemistry 45, 1239312399.

[61] He W, Barrow CJ (1999) The A beta 3-pyroglutamyl and 11pyroglutamyl peptides found in senile plaque have greater beta-sheet forming and aggregation propensities in vitro than full-length A beta. Biochemistry 38, 10871-10877.

[62] Piccini A, Russo C, Gliozzi A, Relini A, Vitali A, Borghi R, Giliberto L, Armirotti A, D'Arrigo C, Bachi A, Cattaneo A, Canale C, Torrassa S, Saido TC, Markesbery W, Gambetti P, Tabaton M (2005) Beta-amyloid is different in normal aging and in Alzheimer disease. J Biol Chem 280, 3418634192 .

[63] Trinchese F, Fa M, Liu S, Zhang H, Hidalgo A, Schmidt SD, Yamaguchi H, Yoshii N, Mathews PM, Nixon RA, Arancio O (2008) Inhibition of calpains improves memory and synaptic transmission in a mouse model of Alzheimer disease. J Clin Invest 118, 2796-2807.

[64] Mueller-Steiner S, Zhou Y, Arai H, Roberson ED, Sun B, Chen J, Wang X, Yu G, Esposito L, Mucke L, Gan L (2006) Antiamyloidogenic and neuroprotective functions of cathepsin B: implications for Alzheimer's disease. Neuron 51, 703-714.

[65] Saito K, Elce JS, Hamos JE, Nixon RA (1993) Widespread activation of calcium-activated neutral proteinase (calpain) in the brain in Alzheimer disease: a potential molecular basis for neuronal degeneration. Proc Natl Acad Sci U S A 90, 26282632.

[66] Tsuchiya K, Kohda Y, Yoshida M, Zhao L, Ueno T, Yamashita J, Yoshioka T, Kominami E, Yamashima T (1999) Postictal blockade of ischemic hippocampal neuronal death in primates using selective cathepsin inhibitors. Exp Neurol 155, 187-194.

[67] Yoshida M, Yamashima T, Zhao L, Tsuchiya K, Kohda Y, Tonchev AB, Matsuda M, Kominami E (2002) Primate neurons show different vulnerability to transient ischemia and response to cathepsin inhibition. Acta Neuropathol (Berl) 104, 267-272.

[68] Inuzuka T, Tamura A, Sato S, Kirino T, Toyoshima I, Miyatake T (1990) Suppressive effect of E-64 c on ischemic degradation of cerebral proteins following occlusion of the middle cerebral artery in rats. Brain Res 526, 177-179.

[69] Tsubokawa T, Yamaguchi-Okada M, Calvert JW, Solaroglu I, Shimamura N, Yata K, Zhang JH (2006) Neurovascular and neuronal protection by E64d after focal cerebral ischemia in rats. J Neurosci Res 84, 832-840.

[70] Cataldo AM, Nixon RA (1990) Enzymatically active lysosomal proteases are associated with amyloid deposits in Alzheimer brain. Proc Natl Acad Sci U S A 87, 3861-3865.

[71] Nakamura Y, Takeda M, Suzuki H, Hattori H, Tada K, Hariguchi S, Hashimoto S, Nishimura T (1991) Abnormal distribution of cathepsins in the brain of patients with Alzheimer's disease. Neurosci Lett 130, 195-198.

[72] Cataldo AM, Paskevich PA, Kominami E, Nixon RA (1991) Lysosomal hydrolases of different classes are abnormally dis- tributed in brains of patients with Alzheimer disease. Proc Natl Acad Sci U S A 88, 10998-11002.

[73] Bernstein HG, Kirschke H, Wiederanders B, Schmidt D, Rinne A (1990) Antigenic expression of cathepsin B in aged human brain. Brain Res Bull 24, 543-549.

[74] Nakanishi H, Tominaga K, Amano T, Hirotsu I, Inoue T, Yamamoto K (1994) Age-related changes in activities and localizations of cathepsins D, E, B, and L in the rat brain tissues. Exp Neurol 126, 119-128.

[75] Zhang J, Goodlett DR, Quinn JF, Peskind E, Kaye JA, Zhou Y, Pan C, Yi E, Eng J, Wang Q, Aebersold RH, Montine TJ (2005) Quantitative proteomics of cerebrospinal fluid from patients with Alzheimer disease. J Alzheimers Dis 7, 125-133; discussion 173-180.

[76] Sundelof J, Sundstrom J, Hansson O, Eriksdotter-Jonhagen M, Giedraitis V, Larsson A, Degerman-Gunnarsson M, Ingelsson M, Minthon L, Blennow K, Kilander L, Basun H, Lannfelt L (2010) Higher cathepsin B levels in plasma in Alzheimer's disease compared to healthy controls. $J$ Alzheimers Dis 22, 1223-1230.

[77] Turk V, Turk B, Turk D (2001) Lysosomal cysteine proteases: facts and opportunities. EMBO J 20, 4629-4633.

[78] Reiser J, Adair B, Reinheckel T (2010) Specialized roles for cysteine cathepsins in health and disease. J Clin Invest 120, 3421-3431.

[79] Vasiljeva O, Reinheckel T, Peters C, Turk D, Turk V, Turk B (2007) Emerging roles of cysteine cathepsins in disease and their potential as drug targets. Curr Pharm Des 13, 387403.

[80] Turk B, Turk D, Turk V (2000) Lysosomal cysteine proteases: more than scavengers. Biochim Biophys Acta 1477, 98-111.

[81] Kuliawat R, Klumperman J, Ludwig T, Arvan P (1997) Differential sorting of lysosomal enzymes out of the regulated secretory pathway in pancreatic beta-cells. J Cell Biol 137, 595-608.

[82] Petanceska S, Burke S, Watson SJ, Devi L (1994) Differential distribution of messenger RNAs for cathepsins B, L and S in adult rat brain: an in situ hybridization study. Neuroscience 59, 729-738.

[83] Reinheckel T, Deussing J, Roth W, Peters C (2001) Towards specific functions of lysosomal cysteine peptidases: phenotypes of mice deficient for cathepsin B or cathepsin L. Biol Chem 382, 735-741.

[84] Satoyoshi E (1992) Therapeutic trials on progressive muscular dystrophy. Intern Med 31, 841-846.

[85] Setoyama K, Koike M, Abe S, Tsutsui Y, Tarumoto Y, Nakane S (1986) Toxicological Studies of Ethyl (+)-(2 S,3 S)-3-[(S)3-methyl-1-(3-methylbutylcarbamoyl)butylcarbamoyl]-2oxiranecarboxylate (EST) (Report 1): Acute Toxicity Studies of EST and Metabolite and By-Product of EST. Iyakuhin Kenkyu 17, 736-743

[86] Fukushima K, Arai M, Kohno Y, Suwa T, Satoh T (1990) An epoxysuccinic acid derivative(loxistatin)-induced hepatic injury in rats and hamsters. Toxicol Appl Pharmacol 105, 1-12.

[87] Ueki S, Watanabe S, Fujiwara M, Shibata S, Shi-yu L, Iwazaki K, Ohta H, Shimazoe T (1986) Effect of cysteine proteinase inhibitor EST on central nervous system. Yakuri to Chiryo 14, 725-735

[88] Hukuhara T, Kimura N, Takano K, Hachiya Y (1985) Effect of EST (E-64-d) on respiratory and cardiovascular functions and central nervous system. Tokyo Jikeikai Ika Daigaku Zasshi 100, 1207-1214.

[89] Miyahara T, Shimojo S, Toyohara K, Imai T, Miyajima M, Honda H, Kamegai M, Ohzeki M, Kokatsu J (1985) Clinical Phase I trial of thiol protease inhibitor (Report 2): safety 
and pharmacokinetics in continuous administration. Rinsho Yakuri 16, 537-546.

[90] Miyahara T, Shimojo S, Toyohara K, Imai T, Miyajima M, Honda H, Kamegai M, Ohzeki M, Kokatsu J (1985) Phase I clinical trial of thiol protease inhibitor EST (Report 1): Safety and pharmacokinetics with single administration. Rinsho Yakuri 16, 357-365.
[91] Watanabe T, Fukushima K, Ushiyama Y, Noda K, Suwa T (1986) Pharmacokinetics of EST (Report 5): Pharmacokinetics of EST ih humans. Kiso to Rinsho 20, 362-366.

[92] Imahori K, Sugita H, Miyatake T, Ishihara T, Miyatani N, Kuwabara T (1985) Pharmacokinetics and safety of thiol protease inhibitor EST in patients with muscle disease. Rinsho Yakuri 16, 749-757. 